\title{
Drilling of Bone: Practicality, Limitations and Complications Associated with Surgical Drill-Bits
}

\author{
Nicky Bertollo and William Robert Walsh \\ Surgical and Orthopaedic Research Laboratories, Prince of Wales Clinical School, \\ University of New South Wales, Prince of Wales Hospital, Sydney, \\ Australia
}

\section{Introduction}

The drilling of bone is ubiquitous in many fields of surgery including orthopaedics, neurosurgery, plastics and reconstructive, craniomaxillofacial and ear nose and throat (ENT). A cylindrical tunnel is typically prepared in bone using a surgical drill-bit to accommodate a screw or other threaded device for rigid fixation which is provided by the integration of bone (cancellous and/or cortical) with the screw threads. In this configuration bone screws are resistant to axial and shear forces as well as bending moments and therefore suited to the load-bearing function of the skeleton during locomotion. Drill-bits are also used in the preparation of bony tunnels, such as in anterior cruciate ligament reconstruction.

Drilling is associated with the conversion of mechanical work energy into thermal energy causing a transient rise in temperature of adjacent bone and soft tissues to above normal physiological levels (Matthews and Hirsch 1972; Lavelle and Wedgwood 1980; Eriksson and Albrektsson 1984; Eriksson, Albrektsson et al. 1984b; Abouzgia and Symington 1996; Natali, Ingle et al. 1996; Toews, Bailey et al. 1999; Bachus, Rondina et al. 2000; Davidson and James 2003; Augustin, Davila et al. 2008; Franssen, van Diest et al. 2008; Bertollo, Milne et al. 2010). Primary sources of this thermal energy are plastic deformation and shear failure of bone and friction at the machining face. The magnitude of this temperature rise is determined by a number of factors, including drill geometry and diameter, rotational speed (rpm), feed-rate $\left(\mathrm{mm} . \mathrm{s}^{-1}\right)$, axial thrust force $(\mathrm{N})$, initial drill-bit temperature and internal or external cooling. The negative effect of elevated temperature on the viability of bone is well-acknowledged and measures to reduce them during surgery are frequently employed, such as manual irrigation with sterile saline (Matthews and Hirsch 1972; Jacob and Berry 1976; Lavelle and Wedgwood 1980; Camargo, Faria et al. 2007; Augustin, Davila et al. 2008). Viability (Eriksson, Albrektsson et al. 1984b) as well as the structure and mechanical properties (Bonfield and Li 1968) of bone are indeed compromised through exposure to elevated temperatures. Another important variable that can influence the biological response for drilled bone is the time which a temperature above a threshold value is maintained.

Excessive temperatures and durations at these elevated levels can result in the necrosis (death) of bone, a phenomenon termed osteonecrosis, or the impairment of osteogenic 
potential. Necrotic bone is resorbed through osteoclastic activity and this can have dire and catastrophic consequences for rigidity of bone screws and pins, ultimately resulting in the failure of fracture repair or implant fixation. Whilst there is no definitive consensus regarding critical values or their durations an increase in temperature of the cortical bone to above $50^{\circ} \mathrm{C}$ has been implicated with a reduced regenerative capacity (Eriksson and Albrektsson 1984; Eriksson, Albrektsson et al. 1984b) and above $56^{\circ} \mathrm{C}$ with osteonecrosis (Matthews and Hirsch 1972). Lundskog (Lundskog 1972) determined cellular necrosis to occur following a 30s duration at above $50^{\circ} \mathrm{C}$ whilst Eriksson and Albrektsson (Eriksson and Albrektsson 1983) demonstrated that a temperature elevation to above $47^{\circ} \mathrm{C}$ which is sustained for one minute has a potent osteonecrotic effect. Both in vitro and in vivo animal models have hitherto played a pivotal role in the determination of these threshold temperatures and critical durations.

The creation of a cylindrical hole or other defect in bone invokes a healing response characterised by the formation of bone reconstituting the defect. To illustrate this point, in the early to mid $20^{\text {th }}$ century the random creation of holes in bone, 8 to 10 depending on the subjective assessment by the surgeon was advocated in the treatment of un-united fractures characterised by the presence of fibrous tissue (Easton and Prewitt 1937). In certain orthopaedic applications such as component fixation in uncemented joint arthroplasty this healing response is crucial in the formation and attainment of a biological and mechanical interlock through bone ongrowth and ingrowth into the porous domain of the implant (Svehla, Morberg et al. 2000; Svehla, Morberg et al. 2002; Bertollo, Matsubara et al. 2011). Excessive temperatures generated during the resection and preparation of bone could hinder postoperative outcome by affecting osteogenic potential. For example, oscillating saw blades used to resect bone in total knee arthroplasty have been shown to experience temperatures in excess of $100^{\circ} \mathrm{C}$ (Larsen and Ryd 1989), with progressively lower temperatures recorded in the bone moving away from the plane of the osteotomy. Similarly, it is not uncommon for temperatures of $100^{\circ} \mathrm{C}$ to be reached during Kirschner wire (k-wire) insertion and drilling of cortical bone. Temperature at the tool-bone interface is notoriously difficult to measure due to the complexities associated with placement of a temperature measurement device at this precise location. Thermocouples and infrared imaging are two measurement modalities used commonly in the experimental determination of temperature elevation in both the in vivo and in vitro settings (Matthews and Hirsch 1972; Augustin, Davila et al. 2008).

The operational environment for a surgical drill-bit is unique and very unlike that experienced by engineering drill-bits used in manufacturing, or traditional non-biological engineering (construction, building, etc). Bone is a complex anisotropic porous viscoelastic composite that is also non-homogenous both in material properties as well as geometry. The outer cortex of bone can be curved and irregular and holes drilled are rarely oriented perpendicular to this surface. In the absence of a pilot indentation to help guide the drill the drill-bit is susceptible to skiving, or wandering, along the cortex prior to purchase, thereby having implications for accuracy as well as final geometry of the cylindrical defect itself. To circumvent this problem the surgeon will often prepare a pilot indentation at a right-angle before positioning the hand-piece and drill-bit at the desired orientation. This is not always desirable as the unnecessary removal of bone stock can compromise screw fixation and pullout strength (Steeves, Stone et al. 2005). Skiving is particularly problematic in the case of bicortical drilling of long bones as the tip can skive along the endosteal surface of the far 
cortex, which induces a bending moment on the fluted portion of the drill-bit (Bertollo, Gothelf et al. 2008). If of sufficient magnitude this bending moment can increase the risk of breakage, with the broken portion sometimes becoming lodged in the medullary canal (Figure 1). The broken fragment is frequently left in situ due to complexities associated with extraction from this confined space (Fothi, Perren et al. 1992; Hirt, Auer et al. 1992). Anatomical constraints, including the presence of muscle as well as blood vessels and nerves also increases the complexity of the use of drills due to possible collateral damage of these structures and subsequent morbidities.

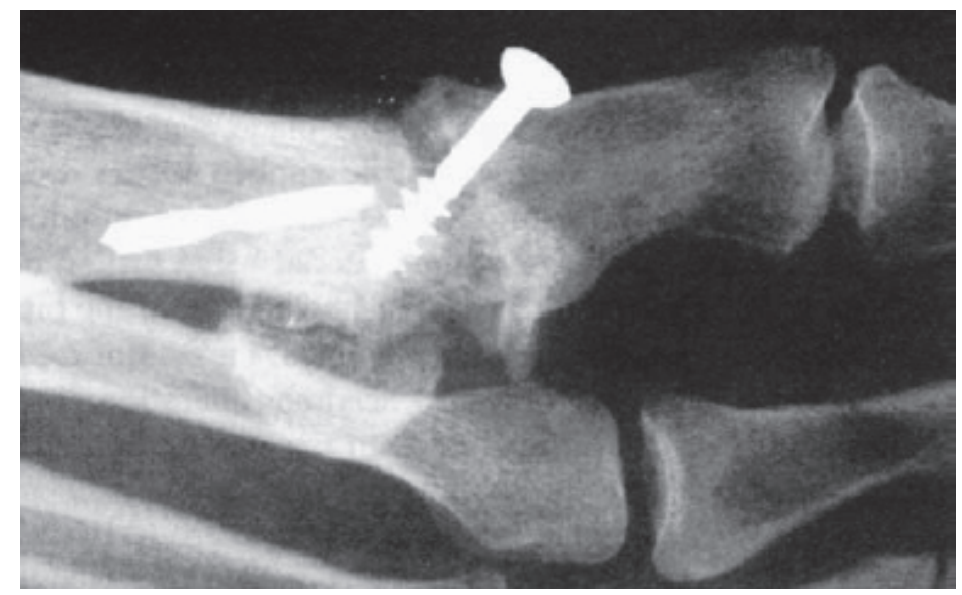

Fig. 1. A broken portion of a drill-bit left in situ. (Natali, Ingle et al. 1996)

Many geometrical and operational variables influence both the performance and maximal temperature elevation in bone as result of the use of drill-bits. Performance and maximal heat generation associated with a particular drill-bit are inevitably interrelated. As has been outlined above, prominent geometric variables include point angle, rake angle, diameter, chisel edge length and flute number. The maximal temperature attained during drilling and the performance of a drill-bit is highly dependent on the specific drill design (Harris and Kohles 2001; Ercoli, Funkenbusch et al. 2004; Chacon, Bower et al. 2006; Bertollo, Milne et al. 2010). Salient operational factors encompass axial thrust force, rotation speed, torque, orthotopic site, sharpness of the cutting edges, irrigation, cooling systems (closed or open loop), initial drill-bit temperature and cortical thickness. Conceivably, blood flow in the vessels and microvasculature contributes in the abatement of maximal temperature attained during drilling. There are very limited reports in the literature pertaining to quantification of this phenomenon. Similarly, bone quality (density as well as microstructure) is another parameter having an effect but which has not been extensively reported. The following sections will address these said operational and geometrical variables.

This chapter will present an overview of the bone cutting process, including heat arising from friction and breakage of molecular bonds and the potential effects which this may have on bone tissue. Factors influencing drill-bit performance and heat generation are also explored, including a review of experimental methods and animal models used hitherto in the determination of the maximal temperature rise and the response of tissue to this thermal insult. 


\section{Drill-bit types}

Surgical twist drill-bits are available in a wide variety of configurations and sizes, with diameters typically ranging from $0.5 \mathrm{~mm}$ to several millimetres. The diameter chosen is application specific but normally the diameter will rarely exceed $14 \mathrm{~mm}$, which would be a diameter required for the preparation and enlargement of medullary canals for intramedullary nails in osteosynthesis. These devices, referred to as reamers can also exhibit flexibility to account for the 'bow' or curvature of long bones, such as the femur which exhibits a slight anterior bow. The main difference between twist drills and reamers is the helix angle (Garcia, Mombiela et al. 2004).

Cannulated drill-bits are another permutation of the surgical drill-bit and are used in procedures such as anterior cruciate ligament reconstruction surgery of the knee, where the orientation of the prepared hole in three dimensions is critical not only for the drill hole but the screw used for fixation (Pinczewski, Lyman et al. 2007). These drills exhibit a hollow cylindrical recess along their length to accommodate smaller diameter pins or k-wires which are driven through the bone at the desired orientation in an intermediary step. The cannulated bit is then passed over this guide-wire and a cylindrical hole produced. The guidewire in this circumstance helps to limit deviation of the drill-bit from the desired orientation. Cannulated drills do not exhibit a chisel edge. A further variation of the cannulated drill is the olive-tipped drill-bit, where the lack of a traditional fluted portion is advantageous as it limits the infliction of damage to the cartilage on the medial condyle whilst allowing the surgeon to position the femoral tunnel at the desired orientation during anterior cruciate ligament reconstruction surgery. That is, the medial condyle is less of a physical obstruction to drilling.

K-wires are another permutation of the surgical drill and are typically used as an intermediary device during surgery to help stabilise or anatomically reduce a fracture, but they can equally be used as a more permanent structure in some cases. Popular k-wires points are the trochar and diamond, although there are others. Reports in the literature seem to suggest that the maximal temperature elevation associated with k-wires is markedly higher than that experienced with fluted drill-bits (Piska, Yang et al. 2002).

Burrs are another type of rotating bone cutting device, used primarily in orthodontic applications, but also occasionally used to decorticate bone in orthopaedic surgery. The design and function of surgical burrs falls outside the scope of this work. However, results in the literature pertaining to temperature rises encountered in the experimental setting during burring is presented and discussed.

\section{Anatomy of a drill-bit}

The medical profession has, with certain exceptions, tended to adapt commercially available instruments that have been developed for drilling other materials (Jackson, Ghosh et al. 1989). A drill-bit consists of a shank which is used to couple the piece to the chuck of the surgical hand-piece, flutes which channel bone chips and debris (swarf) away from the machining face and cutting edges (Figure 2).

The machining face can further be divided into the chisel edge and cutting edges, where the number of flutes exhibited by a drill-bit corresponds to the number of cutting edges. The length of the chisel edge is equivalent to the web thickness of a 2-fluted drill-bit and is also representative of the offset between cutting edges about the axis of rotation. Accordingly, 
the cutting edges produce/exert a slicing action through the material being machined (in this case, bone), thereby explaining why the oblique theory of cutting is applicable to drilling (to be elaborated on in a subsequent section).

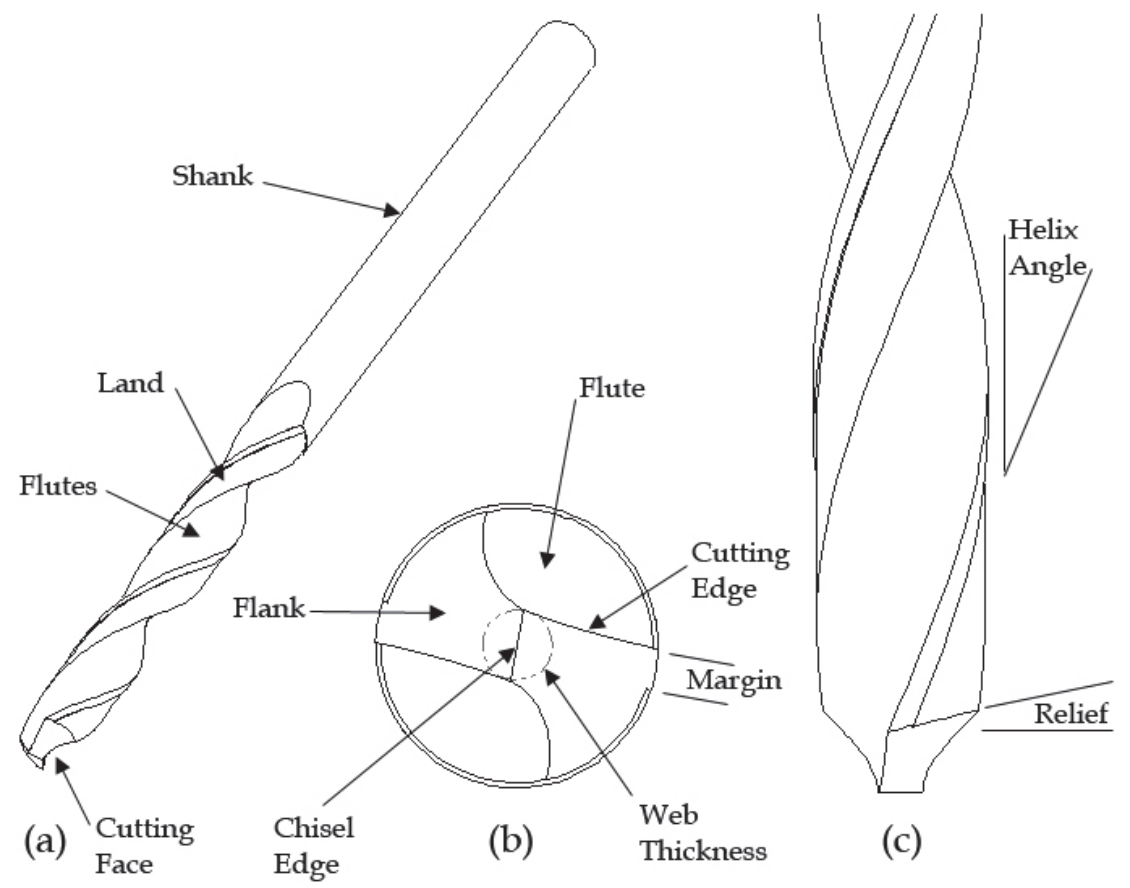

Fig. 2. Drill-bit geometry. (a) General geometry, (b) Point geometry, and (c) Relief and helix angles

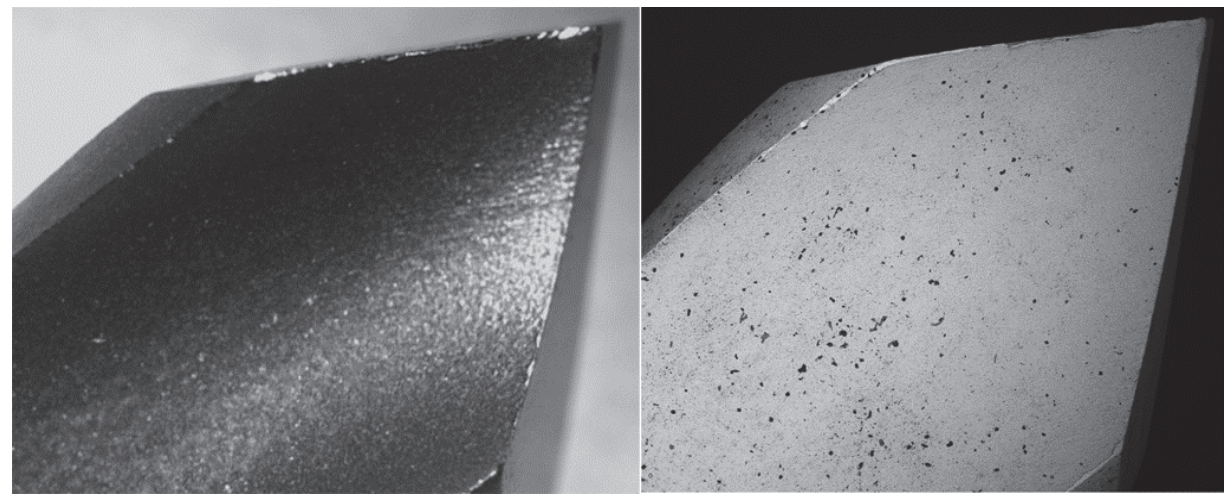

Fig. 3. Macroscopic (left) and scanning electron microscope (SEM) image (right) of a fresh Synthes $4.3 \mathrm{~mm}$ diameter 2 -fluted drill depicting the rake face, cutting edge and point. As an imaging modality SEM provides greater insight into the state and sharpness of cutting and chisel edges 
The chisel edge contributes little to cutting and substantially to the axial thrust force, due to a relatively slow cutting velocity and a large negative rake angle. The extent of the contribution made by the chisel edge to the axial thrust force depends on the length ratio between the chisel and cutting edges. The chisel edge contributes roughly $50 \%$ of the thrust force for a typical drill with a web thickness (chisel edge length) equal to $20 \%$ of the diameter. Where the ratio increases to $30 \%$, the contribution doubles and at $40 \%$ there is a quadrupling of the proportion attributed to the chisel edge length (Stephenson and Agapiou 1997). Several tip design strategies have been aimed at reducing the magnitude of the axial thrust force component attributed to the chisel edge length, one of which is web thinning (Ueda, Wada et al. 2010).

The point angle of a drill is the angle formed by the projection of the cutting edges onto a plane passing through the longitudinal axis of the drill-bit (Figure 4), and is especially relevant in orthopaedics as it prevents the walking of the drill point along the bony surface prior to purchase (Jacobs, Pope et al. 1974; Bertollo, Gothelf et al. 2008). Several optimal point angles for 2-fluted drill-bits have been advanced in the orthopaedic literature. Jacob and colleagues (Jacob and Berry 1976) recommended a point angle of $90^{\circ}$, whilst both Saha (Saha, Pal et al. 1982) and Natali (Natali, Ingle et al. 1996) advocated a value of $118^{\circ}$. This latter point angle is very common for general purpose 2-fluted drills, perhaps because thrust force varies parabolically with the point angle and reaches a minimum value at roughly $118^{\circ}$ (Stephenson and Agapiou 1997).

Point angle has been shown to have little effect on the increase in temperature during drilling. Augustin and coworkers (Augustin, Davila et al. 2008) experimented with $80^{\circ}, 100^{\circ}$ and $120^{\circ}$ point angles in a 2 -fluted drill design in bovine bone showing negligible effect. Likewise, Hillery and Shauib (Hillery and Shuaib 1999) detected no significant difference in temperature elevation in bovine and cadaveric bone in vitro when testing point angles of $70^{\circ}$, $80^{\circ}$ and $90^{\circ}$. Numerical models have also suggested point angle to have a negligible effect on the maximal temperature attained during drilling (Davidson and James 2003).

Ostensibly, a lower limit to the point angle which can be accommodated by 2-fluted drills without compromising the structural integrity of the point exists but which has not been described. Three-fluted drill-bits, on the other hand, are generally able to accommodate a more acute tip angle by virtue of the pyramidal shaped end. We have previously demonstrated that an acute point angle has positive implications for accuracy and targeting ability (Bertollo, Gothelf et al. 2008). In some respects, though, an acute point angle is undesirable as it may result in subsequent damage to muscles, blood vessels and nerves which could contribute to non-primary post-operative morbidity.

The helix angle of a surgical drill is the angle between a tangent to the leading edge of the land and the drill-bit long-axis. The material being machined is the primary variable which determines this parameter; brittle materials producing short chips (such as bone, brass, cast iron, etc) require slow spirals whilst more malleable materials producing longer chips are best handled by drills exhibiting quick spirals. Swarf produced by the cutting action consists of fragments of bone, but is inexorably contaminated with elements which interfere with passage along the flute, namely lipids, marrow, soft-connective tissue and blood, by markedly changing flow characteristics and viscosity. Surgical twist drill-bits are slowspiral, meaning that the helix angle is quite small, making them ideal for the drilling of bone (Jacob and Berry 1976) as debris is ejected quickly. Although flutes are typically parabolic in cross-section, so as to maximise cross-sectional area, when the depth of the hole becomes 
appreciable in relation to its diameter the flutes tend to clog, having direct implications for driving torque and heat generation due to the effects of friction (Natali, Ingle et al. 1996). Cleaning of flutes between successive drilling episodes is therefore mandated. Natali and colleagues suggested the optimal helix angle for surgical drill-bits to be approximately $36^{\circ}$ (Natali, Ingle et al. 1996), actually rendering it a fast helix.
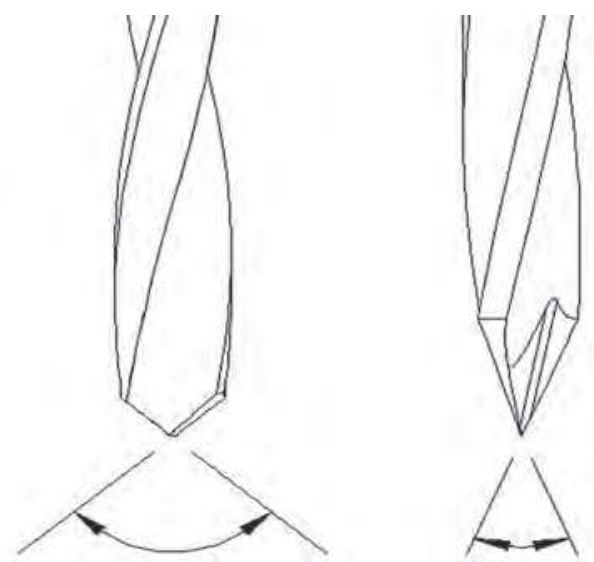

Fig. 4. Point angles of 2-fluted (left) drill-bits are generally less acute than for 3-fluted (right) surgical drill-bits. Web thickness at the tip of 2-fluted drill-bits limits the point angle which can be supported, as compared to the pyramidal shape of the 3-fluted tip

The helix angle of a drill-bit has implications for both rake angle and torsional rigidity (Narasimha, Osman et al. 1987) but has little effect on the maximal temperature elevation (Davidson and James 2003). Narasimha and co-workers (Narasimha, Osman et al. 1987) demonstrated that torsional rigidity varies parabolically with helix angle, reaching a maximum at approximately $28^{\circ}$. They suggested that this may be the reason for the choice of this angle across a wide range of drills used for a multitude of purposes.

Both 2-fluted and 3-fluted surgical drill-bits are in clinical use. Theoretically, 3-fluted drills are inherently more efficient due to the inclusion of an additional cutting face, which can potentially remove $50 \%$ more material per rotation than a diameter-matched 2-fluted drillbit. Additionally, a more acute tip angle in general improves accuracy and targeting ability (Bertollo, Gothelf et al. 2008). Another fundamental difference is the chisel edge length. By virtue of symmetry of 3-fluted designs the cutting edges tend to converge at a single point, committing the chisel edge to a nominal value. As has been shown the ratio of the chisel edge length to the drill diameter is an important parameter in the determination of the effect which this length has on the axial thrust force and cutting efficiency. Despite these theoretical and perceived benefits there is little data in the literature in support of their use.

\section{Cutting operation}

Function of any drill-bit requires the application of rotational motion (rpm) and torque $(\mathrm{N} \mathrm{m})$ which is normally provided by the drill, or hand-piece, and axial thrust force $(\mathrm{N})$ which is applied by the operator manually or via a device such as drill-press. Translation of the machining face through the medium being drilled is defined as the feed-rate 
$\left(\mathrm{mm} . \mathrm{s}^{-1}\right)$. In manufacturing processing and the like a constant feed-rate is normally applied mechatronically whereas in the clinical context a quasi-constant axial thrust force is applied to the hand-piece by the orthopaedic surgeon. This distinction is quite important as pertinent to surgical drill-bit research and the drilling of cortical bone. Appreciably, inter-surgeon variability in axial thrust force applied to a surgical handpiece is considerable. The literature seems to suggest that drill-bit diameter is an important variable affecting the magnitude of this force, although orthotopic drilling site and patient bone quality represent additional considerations. When drilling $3.2 \mathrm{~mm}$ diameter holes in cortical bone we have previously found that the mean thrust force applied by the surgeon to be $110 \mathrm{~N}$ (Bertollo, Milne et al. 2010), Natali and colleagues measured a maximum of between 10 and $20 \mathrm{~N}$ whilst drilling $2.5 \mathrm{~mm}$ diameter holes (Natali, Ingle et al. 1996) whilst Darvish et al (Darvish, Shafieian et al. 2009) applied 50N with a 2.5mm 2-fluted drill-bit. Using 2 to 3.25mm diameter burs Brisman (Brisman 1996) applied loads of $120-240 \mathrm{~N}$ whilst Hobkirk and Rusiniak (Hobkirk and Rusiniak 1977) determined mean values applied during oral surgery to be in the order of 4 and 19N. The relationship between drill-bit diameter and axial thrust force producing a given feed rate is not constant but linear (Allotta, Belmonte et al. 1996).

Wear and dulling of the cutting face due to repeated use has also been shown to have a negative effect on axial thrust force, requiring the application of a higher thrust force to produce a hole in bone. This can have unintended complications, such as cortical breakthrough and uncontrolled plunging of the drill-tip. The effect of these variables on drill operation will be explored in detail in the following sections.

The cutting of bone is a dynamic shear failure process (Jacob, Pope et al. 1974). A primary source of heat in the drilling process is the release of energy through the mechanical overwhelming of intermolecular bonds. An idealised illustration of the oblique cutting process is shown in Figure 5.

The removal of bone at the machining face is achieved by the cutting edges which remove a finite thickness of material, $t$, with each rotation as they spiral through the bone, following a helical path. The material being machined is associated with a unique cutting force, and this determines the optimal rake angle, which for cortical bone is 25 to $35^{\circ}$ (Jacob and Berry 1976). Unlike many engineering materials cortical bone is mechanically and structurally anisotropic, which has implications for the machining operation and cutting resistance. This is because as the drill-bit rotates the cutting resistance vector is constantly changing. Jacob and colleagues (Jacob, Pope et al. 1974) demonstrated the dependency of the cutting process on the osteon direction in cortical bone, where the cutting forces were greatest when cutting perpendicular to the osteon direction. Based on this work pertaining to orthogonal cutting it was established that a rake angle of $45^{\circ}$ is associated with a markedly reduced cutting force, regardless of the osteon direction.

Jacob and Berry (Jacob and Berry 1976) went on to investigate the effect of drill geometry on axial thrust force and drilling torque. They essentially found an asymptotic relationship between both axial thrust force and torque with increasing rotation speed, providing that the feed rate remained constant. Based on their results they suggested that orthopaedic drillbits should have an appreciable rake angle $\left(25\right.$ to $\left.35^{\circ}\right)$, exhibit a point angle to prevent walking of the drill-bit tip prior to purchase, drilling should be done in the 750 to $1250 \mathrm{rpm}$ range and performed in the presence of a cooling agent. Further support for this rotation rate was provided by Hillery and Shuaib (Hillery and Shuaib 1999) who recommended a range of 800 to1400rpm. 

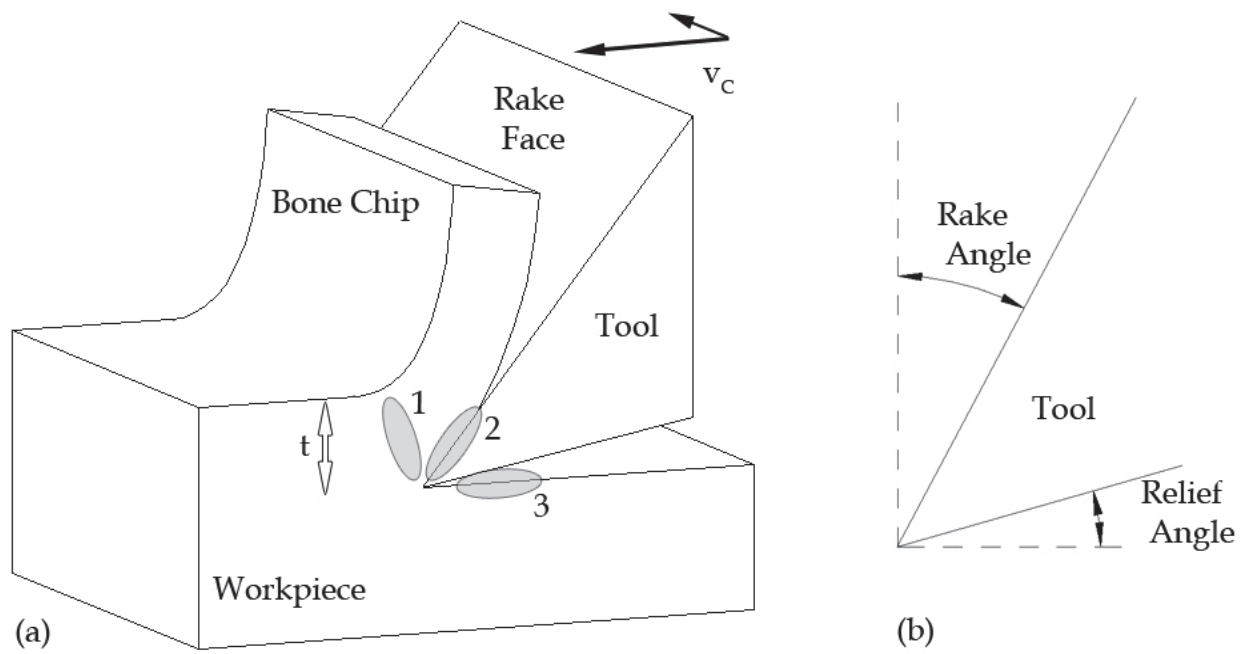

Fig. 5. (a) Mechanism of action of material removal at the rake face during oblique cutting. Regions of primary heat generation are also indicated; 1 : shear deformation of the bone, 2 : friction between the bone chip and tool and (3) friction between the tangential bone surface and tool. Note that in regions 2 and 3 slight deformation of bone is occurring, also. (b) Rake and relief angles

A relief angle in the design of drill-bits is optional but is often incorporated into the cutting process to relieve the thermal loading and mechanical inefficiencies arising from frictional drag between the surface tangential to the direction of cutting and tool. The in vitro work of Chacon et al (Chacon, Bower et al. 2006) suggests that relief angle has a significant effect on the magnitude of the maximal temperature rise during drilling of bone.

According to Allotta et al (Allotta, Belmonte et al. 1996) the relationship between thrust force and drill-bit diameter is approximately linear and not constant. Therefore, testing different diameter versions of the same drill-bit design at similar feed-rates may have a potentially confounding effect on the maximum temperature elevation. This is because at larger diameters a given feed-rate is associated with larger axial thrust forces. Many previous investigators have demonstrated that the maximum temperature elevation of bone is particularly sensitive to axial thrust force. To test multiple diameters of a single version of a drill at a particular feed rate has the potential to produce spurious results.

\subsection{Heat generation and thermodynamics}

The primary sources of thermal energy (heat) generation during drilling of bone are shear deformation of bone (1), friction between the bone chip and the rake face (2) as well as friction between cutting edge and underlying bone (3) (Figure 5). Secondary indirect heat sources are driven purely by friction, including that in occurrence between bone chips and flutes, bone chips and host bone and drill-bit webbing and host bone. It has been estimated that approximately $60 \%$ of the heat energy generated during drilling is dissipated by bone chips, which is substantially less than the $80 \%$ predicted to be removed by the chips during drilling of metals. The remainder of the heat is dissipated by the surrounding hard and soft tissues as well as by the drill-bit itself, causing a transient rise in temperature to above 
normal physiological levels. Numerical and mathematical models are best suited to the analysis of heat generation and transfer during the drilling operation.

Thermal conductivity is a thermodynamic parameter which describes a material's ability to conduct heat. Cortical bone, as a composite material consisting of organic (collagen) and inorganic (hydroxyapatite) phases, is a relatively poor conductor of heat. Davidson and James (Davidson and James 2000) demonstrated that bovine cortical bone is thermally isotropic, with thermal conductivity in the axial, radial and tangential directions being approximately $0.58 \mathrm{~W} / \mathrm{Km}$, which is in direct contrast to the anisotropic structural and mechanical properties. Thermal conductivity of surgical-grade stainless steel (316L), on the other hand, is of the order of $16.3 \mathrm{~W} / \mathrm{mK}$. Specific heat is another important material property (Chen and Gundjian 1976) in the determination of the maximal temperature attained by bone in the presence of a heat source. It has been demonstrated that the maximum temperature attained by cortical bone during drilling is more sensitive to changes in specific heat (heat capacity) than to thermal conductivity (Davidson and James 2003).

\section{Mechanical properties}

Surgical drills must be able to withstand the driving torques, axial thrust forces, shear forces and bending moments imparted to them during operation. The grinding of flutes into a solid rod (known in machining terms as a blank) to produce a drill-bit significantly alters both the rotational and bending stiffness properties. In the presence of excessive driving torques a drill bit can unravel (Narasimha, Osman et al. 1987), but this is rarely reported complication in the orthopaedic literature. Drill-bits are routinely subjected to bending loads, such as those depicted in Figure 6.

Three modes of bending are depicted in Figure 6; bending scenarios a and $\mathrm{b}$ relate to measures taken by the surgeon to counter the likelihood of the drill-tip to skive. Bending scenario $c$ describes the situation where the drill-tip skives along the endosteal surface of the far cortex, inducing a bending moment. As the surgeon is blinded to activity at this location he or she cannot toggle the handpiece to compensate for this skiving and relieve the built-up bending moment. The idealised drill-bit depicted in the following figure responds to the moments and shear loads by deforming in the $x-z$ plane of the global reference frame, the extent of which is governed by the flexural rigidity (EIx), which is a function of the material properties (Young's modulus, E - MPa) and second (area) moment of inertia $\left(\mathrm{Ix}-\mathrm{mm}^{4}\right)$ of the drill's cross section. Surgical drills are typically manufactured from surgical grade stainless steel (316L), although an alloy of titanium $\left(\mathrm{Ti}_{6} \mathrm{Al}_{4} \mathrm{~V}\right)$ has also been used (Jochum and Reichart 2000). The physicochemical properties of these materials falls outside the scope of this work and will not be elaborated further.

\subsection{Second (area) moment of inertia - I}

The deformation profile in the $y-z$ plane of a solid cylindrical bar subjected to the conditions depicted in the preceding figure would be, like the cross-sectional area uniform and therefore independent of drill-bit rotation. Conversely, the response of the fluted portion of a 2-fluted drill-bit is a function of both the cross-sectional area and rotation relative to a global reference frame. A cross-sectional view of the fluted portion of a 2-fluted drill-bit is shown in Figure 7. 

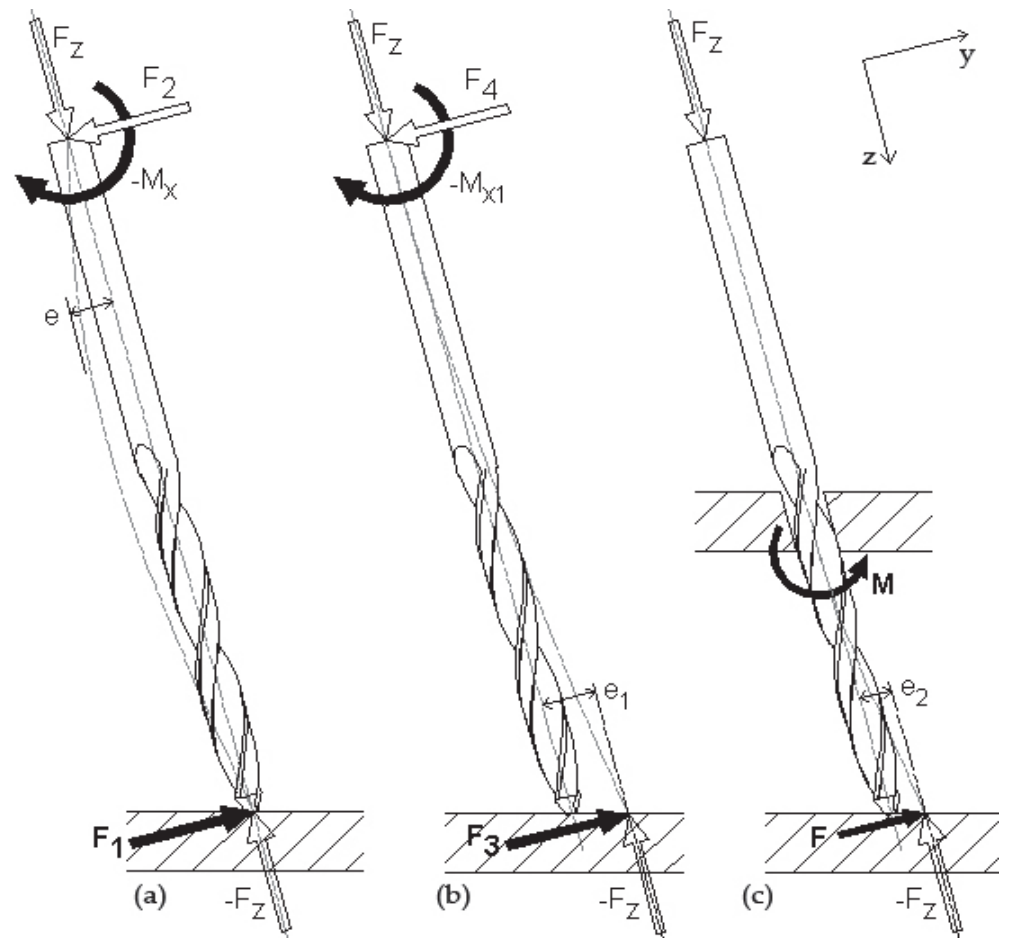

Fig. 6. Bending modes for a surgical drill. The deformation profile of the two-fluted drill-bit under each scenario is idealised and does not take into account the variation in second (area) moment of inertia properties along the length of the drill. (Bertollo, Gothelf et al. 2008)

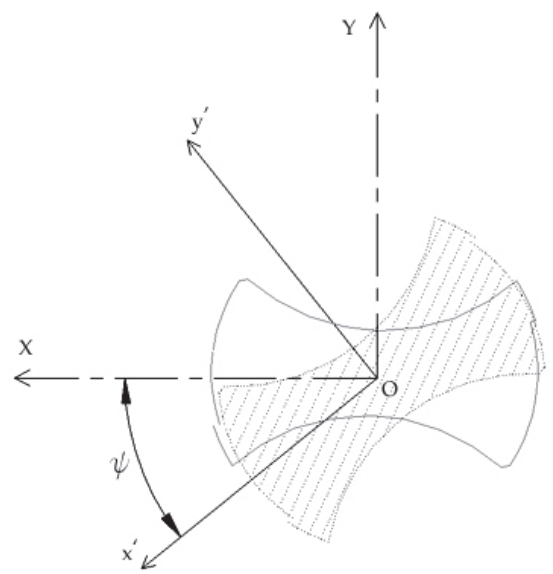

Fig. 7. Cross-section of a typical 2-fluted orthopaedic drill-bit. The second (area) moment of inertia of the fluted portion of the drill changes with rotation, $\psi$, of the cross-section relative to the global $(x-y)$ coordinate system 
In the above figure the $x-y$ axes indicate orientation of the global reference frame, whilst the $x^{\prime}$ and $y^{\prime}$ axes are axes of symmetry of the cross-section. The second (area) moment of inertia, $\mathrm{I}_{\mathrm{X}}$, at any point along the length of the fluted portion of the drill as a function of drill rotation, $\psi$, is given by:

$$
l_{x}=\int_{A} y^{2} d A=\left[\frac{l_{\max }+l_{\min }}{2}+\frac{l_{\max }-l_{\min }}{2} \sin 2 \theta-l_{x y} \sin 2 \varphi\right]
$$

where $I_{\max }$ and $I_{\min }$ is the moment of inertia taken about the $x^{\prime}$ and $y^{\prime}$ axes. As such, $I_{\max }$ and $I_{\min }$ are the principal moments of inertia. Furthermore, due to the symmetry inherent in the section the product of inertia, $\mathrm{I}_{\mathrm{xy}}$, tends to zero, such that the $\mathrm{I}_{\mathrm{x}}$ of a 2-fluted drill-bit is therefore given by:

$$
l_{x}=\left[\frac{l_{\max }+l_{\min }}{2}+\frac{l_{\max }-l_{\min }}{2} \sin 2 \varphi\right]
$$

The polar moment of inertia, $\mathrm{I}_{\mathrm{Z}}$, determines the torsional rigidity of the drill which is independent of rotation is given by:

$$
l_{z}=l_{\max }+l_{\min }
$$

Where the torque applied to the drill overwhelms the polar moment of inertia the drill begins to unravel. There is anecdotal evidence to suggest that this type of failure mode does occur but is extremely rare.

In our previous work we have demonstrated that the Ix profile varies along the length of a 2fluted drill-bit with rotation (Figure 8). Conversely, Ix of a 3-fluted drill does not vary as a

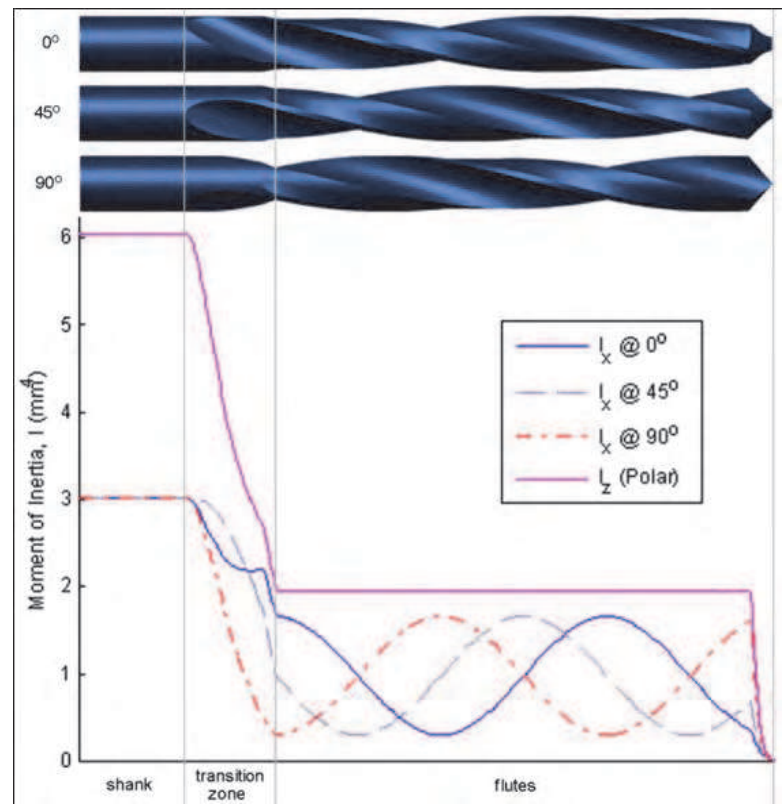

Fig. 8. $\mathrm{I}_{\mathrm{X}}$ and $\mathrm{I}_{\mathrm{Z}}$ profiles for a 2-fluted drill-bit. (Bertollo, Gothelf et al. 2008) 
function of rotation (Figure 9). This property occurs as a result of the inherent symmterical arrangement of material about the prinical axes, such that the principal moments of inertia $\left(\mathrm{I}_{\max }\right.$ and $\mathrm{I}_{\max }$ ) are equal in magnitude and the relation in equation 2 becomes independent of rotation.

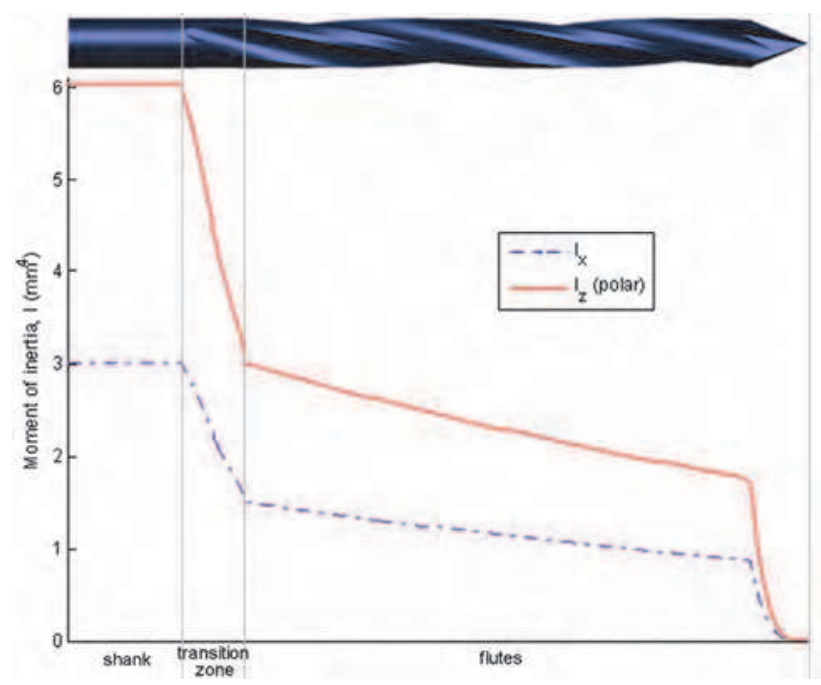

Fig. 9. IX and Iz profiles for a 3-fluted drill-bit. (Bertollo, Gothelf et al. 2008)

Two-fluted drills tend to deflect in the weaker principal direction under the action of a bending moment. Whilst the $I_{X}$ and $I_{Y}$ profiles for presented figures 8 and 9 are based on two different drill types the same general result applies to all drills. It follows that the flexural rigidity of 2-fluted and 3-fluted drill-bits are inherently different; this property varies as a function of rotation for 2-fluted drills but not 3-fluted drill-bits (Stephenson and Agapiou 1997; Bertollo, Gothelf et al. 2008). This has direct implications for the extent of skiving whilst drilling at oblique orientations as well as drill-bit breakage under the application of a bending moment (Bertollo, Gothelf et al. 2008). Generally, a diametermatched three-fluted drill-bit is less likely to fail under the application of a bending moment.

\section{Wear and dulling of the cutting face}

Cutting edges of the drill-bit are mechanically and thermally loaded during machining. Cumulative wear at the cutting face has a deleterious effect on cutting efficiency of surgical drill-bits. This is manifest as a patent increase in the required axial thrust force, an increase in maximal temperature of bone and the initiation of vibration (due to an increase in surface roughness of the cutting edges). Scanning electron microscopy (SEM) is one imaging modality which can be used to analyse wear at the cutting edges. The primary types of wear seen at the cutting tip are abrasive wear and plastic deformation (Ercoli, Funkenbusch et al. 2004; Allan, Williams et al. 2005a; Marciniak, Z. Paszenda et al. 2007), which irreversibly modifies the dimensions and geometry of the chisel and cutting edges, as well as the rake face. Craters can also form on the rake face. Allan and colleagues (Allan, Williams et al. 
$2005 b)$ investigated the effects of differing degrees of wear on maximum temperature elevation in cortical bone in vitro. Holes were drilled in porcine mandibles using drill-bits (1.5mm diameter, 2-fluted Leibinger) which were fresh, used in the preparation of 600 holes and taken directly from theatres and temperatures recorded. Six-hundred holes was the amount required to produce a statistically significant elevation in temperature compared to the fresh drill-bits (control). The extent of wear at the cutting face can be seen in Figure 10.

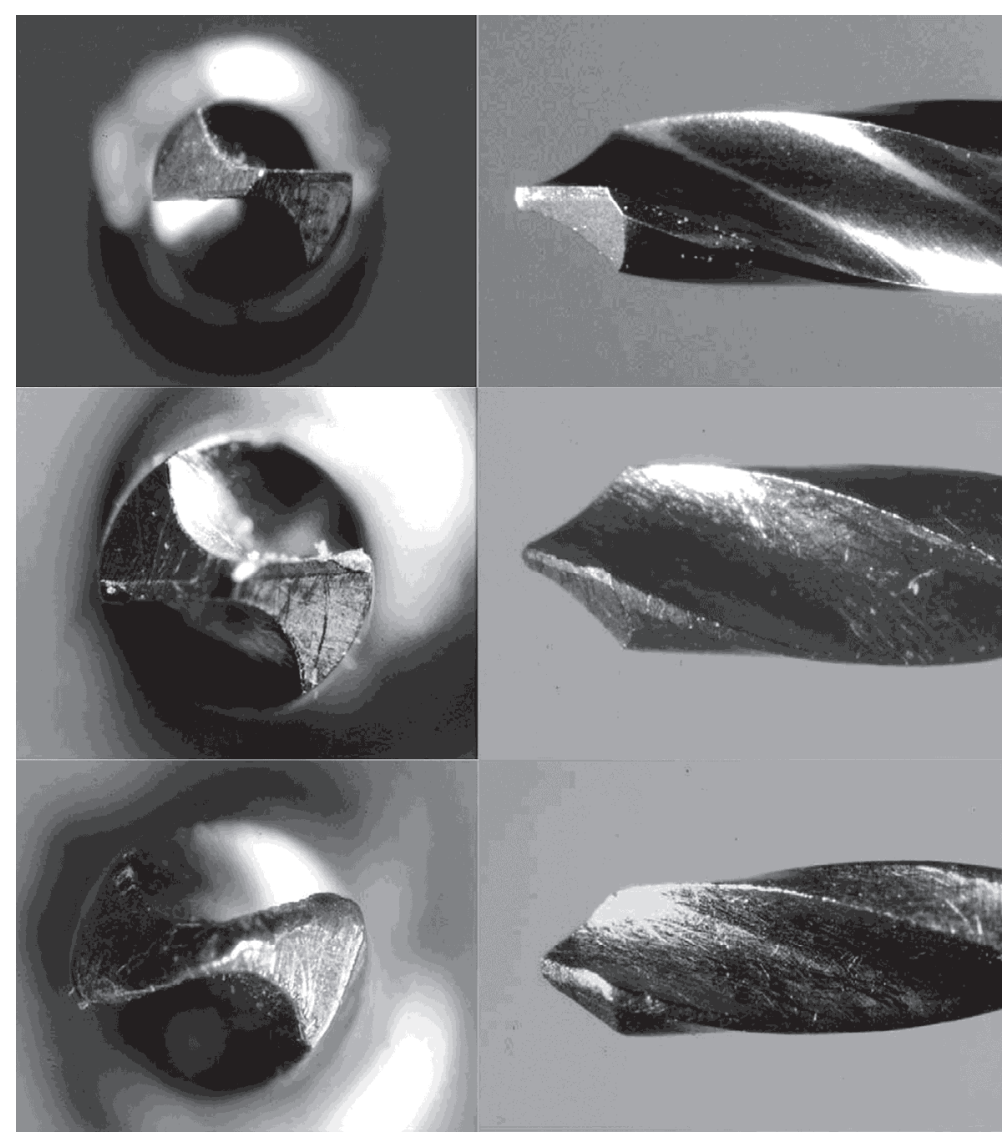

Fig. 10. End and side image taken of three $1.5 \mathrm{~mm}$ diameter 2-fluted Leibinger drill-bits. Top: fresh. Middle: following the drilling of 600 holes. Bottom: Drill-bit taken directly from theatres. The drill-bit depicted has a split-point design. (Allan, Williams et al. 2005b)

In the above figure substantial wear of the chisel and cutting edges can be seen in the drillbit following the preparation of 600 holes. In the case of the drill-bit taken from theatre wear is so extreme that both chisel and cutting edges are virtually indistinguishable. There was no indication given as to the estimated number of orthopaedic procedures this particular drillbit was utilised in. It is not surprising that in their study a linear relationship between maximal temperature rise and wear was detected, with a maximum $54.5^{\circ} \mathrm{C}$ measured using the drill obtained directly from theatres. 
Seventy-five percent of surveyed hospitals in the United Kingdom do not routinely monitor their surgical instruments for sharpness and wear (Singh, Davenport et al. 2010). Up to $45 \%$ of hospitals surveyed in the United Kingdom are utilising single-use drill-bits (Singh, Davenport et al. 2010), but for all intents and purposes orthopaedic surgical drill-bits are multiple-use items (Ashford, Pande et al. 2001). They are distinctly different from oscillating saw blades (another source of heat generation) and other cutting tools used in orthopaedic surgery in that they are not considered or treated as consumables.

Many researchers from both the maxillofacial and orthopaedic sub-specialities have demonstrated a positive correlation between repeated use and maximal temperature elevation. Jochum and Reichart (Jochum and Reichart 2000) demonstrated the effects of repeated drilling on the maximal temperature rise in bone, showing a positive correlation in the porcine mandible. In this study holes were created by a single operator whilst applying only minimal pressure. Harris and Kohles (Harris and Kohles 2001) employed a polymeric test bed to assess the effects of repeated use and sterilisation on drilling performance, concluding that there is a negative correlation with both. Chacon and co-workers (Chacon, Bower et al. 2006) also encountered increased temperature elevation and visual wear signs with successive drilling episodes using a combination of 2- and 3-fluted drills in bovine femurs in vitro. Earlier, Matthews and Hirsch (Matthews and Hirsch 1972) demonstrated a negative relationship between wear through repeated use and magnitude of the maximal temperature elevation in cadaveric femora. Garcia et al (Garcia, Mombiela et al. 2004) studied the effects of intramedullary reaming on cortical bone temperatures in an in vivo minipig model. Using the same instruments in all preparations the maximum temperatures encountered became progressively greater, reaching as high as $49.4^{\circ} \mathrm{C}$, but was not associated with any histological evidence of osteonecrosis.

Considering the cost of a single drill-bit can be more than USD $\$ 100$ a more economical alternative is reconditioning and reprocessing surgical drill-bits when they become blunt. Darvish et al (Darvish, Shafieian et al. 2009) investigated the ability of this process to restore the pristine geometry of the cutting tip, by measuring parameters such as lip length, chisel edge length and chisel edge angle and subsequently found that drilling efficiency was most sensitive to chisel edge length and angle.

Protective coatings have been applied to drills with the intention of improving durability but which have not been shown to be entirely effective (Ercoli, Funkenbusch et al. 2004). Another important consideration is delamination of these coatings during the cutting process as they may elicit a foreign body reaction when left in situ.

\section{Complications}

Intraoperative complications associated with the use of drill-bits includes drill-bit breakage (Fothi, Perren et al. 1992; Hirt, Auer et al. 1992; Benirschke, Melder et al. 1993; Miller 2002; Price, Molloy et al. 2002; Matthews, Landsmeer et al. 2006; Bodner, Woldenberg et al. 2007; Bassi, Pankaj et al. 2008; Pichler, Mazzurana et al. 2008; Gupta, Singh et al. 2009; Kosy and Standley 2010) and heat generation (Berning and Fowler). Another cause for concern, albeit a rarely reported complication, is microfracture of host bone adjacent to the drilled defect. This can occur as a consequence of the jarring action associated with cutting a structurally isotropic material that is bone, the severity of which can be exacerbated by a blunted drill-tip.

Excessively high temperatures may be generated at the orthotopic drilling site during the surgical procedure. The maximal rise in temperature during surgery is determined by a 
number of operational variables including axial thrust force, drill-bit diameter, rotational speed, provision of irrigation and condition of the cutting tools .i.e. extent of fouling and blunting of the surgical drill-bit. Maximal temperatures in excess of $100^{\circ} \mathrm{C}$ are not uncommon during the machining of bone with rotational cutting tools.

Whilst minimising the duration and magnitude of the maximum temperature elevation during the machining of bone during drilling and burring is of paramount importance and concern for the surgeon, consideration must also be given to the frictional heat and temperatures generated in the bearings of high-speed drills and drivers. At these speeds frictional heat within the tools themselves can produce temperatures in excess of $60^{\circ} \mathrm{C}$ which can produce burns in the mouth of the patient or to tissue adjacent to the surgical site, as well to others handling the instrument (Anonymous 2008).

\subsection{Intraoperative complications}

\subsubsection{Drill-bit breakage}

It is reported that the drill-bit is the most frequently broken surgical instrument (Fothi, Perren et al. 1992; Hirt, Auer et al. 1992; Miller 2002; Price, Molloy et al. 2002; Pichler, Mazzurana et al. 2008) which represents a considerable dilemma for surgeons due to the complexities associated with removal of the broken portion from either the bone or medullary canal (Matthews, Landsmeer et al. 2006; Bassi, Pankaj et al. 2008). Actual breakage rates have been reported to vary between $0.14 \%$ (11/7,775 orthopaedic cases) (Price, Molloy et al. 2002), 0.194\% (23/11,856 orthopaedic cases) (Pichler, Mazzurana et al. 2008) and $0.3 \%$ (3/1000 internal fixation procedures) (Hirt, Auer et al. 1992). It is generally agreed that actual rates are higher but that this complication is frequently under-reported. The primary reason for failure is the application of an excessive bending moment during operation, which overwhelms the bending strength (Flexural Rigidity, EI) of the drill-bit.

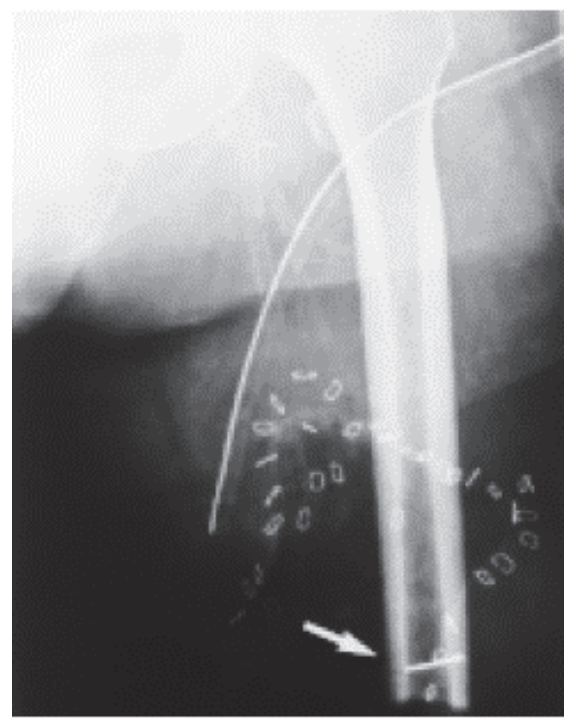

Fig. 11. Radiograph of a broken drill-bit embedded in a femur and left in situ. (Wolfson, Seeger et al. 2000) 
Surgical drill-bits are manufactured from biologically inert materials and broken portions for this reason can be left in situ without any complications or concern. An important consideration for the surgeon, however, is whether a broken fragment is in contact with an implant as micromotion can generate wear particles and possibly metal ions. If sufficiently large these particles, whose physical size precludes them from being digested may elicit an inflammatory response resulting in osteolysis.

\subsubsection{Heat generation}

Drilling is also associated with the generation of thermal energy, causing a transient rise in temperature of bone and soft tissues as well as the drill-bit itself. Due to definite limitations imposed on intraoperative measurement of temperature the examination of bone drilling and heat generation has typically been performed in the in vitro laboratory setting by research groups from many surgical sub-specialities, including the orthopaedic, dental, maxillofacial and neurological fields. In vivo animal models (to be explored in a later section) have provided an additional biological endpoint in the determination of the reaction of cortical bone to heat exposure. Several seemingly subtle but fundamental differences between these studies, both in terms of the hardware (drills versus burs) as well as applied axial thrust force and drilling rotational speed exist. High speeds of 10,000 to 400,000rpm are routinely used for drilling and burring in dental applications, whilst considerably lower speeds (less then 1000rpm) are typically used in orthopaedic procedures. There seems to be little consensus in the literature, however, regarding the effects of these and other operational variables on the magnitude of the maximal temperature elevation in cortical bone. Furthermore, the reported range in maximal temperatures measured across these said experiments is also substantial.

Matthews and Hirsch (Matthews and Hirsch 1972) frequently measured maximum temperatures well in excess of $100^{\circ} \mathrm{C}$ whilst drilling holes in cadaveric femora with a $3.2 \mathrm{~mm}$ diameter 2-fluted drill. They found increasing rotation speed from 345 to 2900 prm to have little influence on the maximal temperature attained. Conversely, increasing axial thrust force from approximately 20 to $120 \mathrm{~N}$ was associated with decreases in both maximum temperatures and their durations. Augustin et al (Augustin, Davila et al. 2008) likewise provided evidence for a reduction in peak temperature by increasing the feed rate. A limitation of their study is that the relationship between feed-rate and axial thrust force as a function of drill-bit diameter was not presented. In cadaveric femurs Bachus and colleagues (Bachus, Rondina et al. 2000) encountered both a reduction in magnitude and duration of the maximum temperature with increasing axial thrust force $(53,83,93$ and $130 \mathrm{~N})$ in the absence of irrigation using $3.2 \mathrm{~mm}$ diameter drills at $820 \mathrm{rpm}$. Hillery and Shauib (Hillery and Shuaib 1999) detected a significant decrease in the magnitude of the maximal temperature elevation with increasing drill speed (400 to $2000 \mathrm{rpm}$ ), also at a diameter level of $3.2 \mathrm{~mm}$.

Sharawy and co-workers (Sharawy, Misch et al. 2002) demonstrated a reduction in temperature elevation with increasing rotation rate (1225 to $2500 \mathrm{rpm}$ ) across a range of drill-bit diameters ( 1.5 to $4.2 \mathrm{~mm}$ ) during manual drilling of porcine mandibles. The drilling systems used in this study were both internally and externally irrigated. Iyer et al (Iyer, Weiss et al. 1997a) likewise found an inverse relationship between drill speed and the maximal temperature elevation in rabbit tibiae. Intraoperative measurements were made with the animal sedated whilst using burs to create cylindrical defects at low (2500rpm), 
intermediate $(100,000 \mathrm{rpm})$ and high $(400,000 \mathrm{rpm})$ rotation speeds. Intermittent pressure was applied by a single surgeon during drilling. Also using 2 to $3.25 \mathrm{~mm}$ diameter burrs from the dental realm Brisman (Brisman 1996) demonstrated that increasing both axial thrust force and rotation speed independently from 120 to $240 \mathrm{~N}$ and 1800 to $2400 \mathrm{rpm}$, respectively, causes an increase in maximal temperature elevation. Conversely, increasing both rotation rate and axial thrust force concurrently had no effect on temperature and simultaneously increased drilling efficiency. Whilst this data was derived using burrs and is therefore not directly applicable to drill-bits these results do suggest that these operational variables can have a synergistic effect on temperature elevation.

Investigating burring speeds from 400 to $40,000 \mathrm{rpm}$ on temperature elevation in bovine cortical bone Reingewirt et al (Reingewirtz, Szmukler-Moncler et al. 1997) identified a pseudo-bimodal correlation between rotation speed and maximal temperature elevation, which correlated positively from 400 to $7,000 \mathrm{rpm}$, at which point the correlation became negative. At lower speeds ( 400 to $800 \mathrm{rpm}$ ) enhanced axial thrust force ( 80 to $200 \mathrm{~N}$ ) had no effect on temperature. Using similar tissue and hardware, Krause (Krause, Bradbury et al. $1982)$ found that the effects of increased rotation speeds $(20,000$ to $100,000 \mathrm{rpm})$ on temperature were dependent on the type of bur. In other words, the magnitude of the maximal temperature rise was more sensitive to geometric variables.

As has been shown there appears to be little agreement in the in vitro literature regarding the effects of rotational speed, feed-rate and thrust force on the maximal temperature attained during the drilling of bone, which may be indicative of the significant effects of drill-bit geometry on the maximal temperature elevation. Davidson and James (Davidson and James 2003) used a finite element (FE) model to demonstrate a positive relationship between maximum temperature and rotation speed, feed rate and axial thrust force, as well as a quasi-linear relationship between maximal temperature elevation and drill diameter. Their model, however, did not take into account the transfer of heat between bone chips and rake face of the tool nor friction between the cutting edge and new surface (regions 2 and 3 in Figure 5, respectively). Other FE models (Lee, Rabin et al. 2011) have taken these effects into account and demonstrated that the convection of heat at this interface and along the length of the fluted portion has a substantial effect on heat dissipation during drilling.

Toews and colleagues (Toews, Bailey et al. 1999) examined the effect of feed rate and drill speed on the maximal temperatures recorded in equine bone and found increasing feed rate was associated with decreased maximal temperature, whilst increasing rotation speed (317 to $1242 \mathrm{rpm}$ ) increased mean maximal temperature. Increasing cortical thickness was also positively correlated with increasing mean maximal temperature. Cortical bone is of a finite thickness, which has definite implications for temperature elevation. One would reasonably surmise that increased axial force and feed rate would produce lower temperatures purely as a function of reduced drilling time. Cordioli and others (Cordioli and Majzoub 1997) demonstrated a clear relationship between drilling depth and maximum temperature in bovine femurs with 2 and $3 \mathrm{~mm}$ diameter drills operating at 1500rpm with 200N applied axial load. Using cadaveric and bovine bone with markedly different cortical thicknesses Hillery and Shuaib (Hillery and Shuaib 1999) encountered significantly higher temperatures in bovine bone than in human bone whilst keeping the operational and geometric parameters constant. They attributed this result to the difference in mean cortical thickness between the cadaveric ( 3 to $5 \mathrm{~mm}$ ) and bovine $(7$ to $9 \mathrm{~mm}$ ) samples. Eriksson et al (Eriksson, Albrektsson et al. 1984a) measured in vivo temperature elevations during drilling of rabbit, 
dog and human tibiae, encountering temperatures of $40^{\circ}, 56^{\circ}$ and $89^{\circ}$, respectively, under similar conditions. The differences in this study were also attributed to the difference in cortical thickness between species.

We recently tested the cutting efficiency and thermal profile of commercially available 2- and 3-fluted 3.2mm diameter surgical drill-bits in porcine bone in vitro (Bertollo, Milne et al. 2010). Characteristic feed rates for each drill-bit at the experimentally-determined upper and lower 95\% CI bounds of axial thrust force were determined, with both 3-fluted drills requiring significantly higher feed rates to reproduce these forces. Despite the finding of improved cutting efficiency for the 3-fluted drills, this did not translate into a significant and parallel reduction in maximum cortical temperatures for both 3-fluted drills either in the presence or absence of external cooling.

Many investigators have examined the effects of operational drilling parameters on the maximal temperature experienced during drilling of bone. A large proportion of these studies have assumed that drilling speed remains constant during drilling and this may not be the case. Abouzgia and James (Abouzgia and James 1995) demonstrated that rotational speed decreases by as much as $50 \%$ during drilling.

\subsubsection{Intraoperative temperature abatement strategies}

In orthopaedic surgery external irrigation with sterile saline delivered via a syringe or other device is routinely applied during drilling, the efficacy of which has been demonstrated by several authors (Matthews and Hirsch 1972; Jacob and Berry 1976; Lavelle and Wedgwood 1980; Krause, Bradbury et al. 1982; Kondo, Okada et al. 2000; Camargo, Faria et al. 2007; Augustin, Davila et al. 2008; Sener, Dergin et al. 2009). Utilising a numerical model, Lee and co-workers (Lee, Rabin et al. 2011) modelled the effect of coolant applied to the shank and exposed fluted portion of the operational drill-bit, demonstrating that this application may have a significant effect on the maximum drill temperature, even in the advanced stages of drilling where the cutting face is embedded deep in the bone. This has important implications in the case of bi-cortical drilling as this result suggests that coolant applied to the shank may act to limit/reduce the maximal temperature experienced at the isolated far cortex, and is due to the relatively high thermal conductivity of surgical-grade stainless steel compared to bone.

Closed-loop and open internal cooling systems are available but are primarily limited to orthodontic and dental applications (Haider, Watzek et al. 1993; Sharawy, Misch et al. 2002; Silverstein 2007). Closed-loop cooling systems are those in which coolant courses through tubules and tunnels incorporated into the drill-bit or bur itself and back through a central heat exchanger. Thermal energy generated at the machining face heats the coolant through a mechanism of conduction, thereby preventing an increase in temperature of the bone to above a critical level. In open cooling systems fluid courses through tubules in the drill but exits through openings at the cutting tip, thereby absorbing heat but also providing some lubrication in the process of cutting. This, of course depends on the precise location of the outlet(s) in relation to the cutting edges. Strictly speaking, however, the application of coolants by external means does not lubricate the cutting process, as it is applied against the direction of swarf flow.

Using an ovine model, Haider and colleagues (Haider, Watzek et al. 1993) compared the biological response of compact (cortical) and spongy (cancellous) bone to implants placed into defects created in the presence of both internal and external manual cooling. Interestingly, on the basis of histological results at 4 weeks following implantation it was 
found that externally applied manual cooling versus internal cooling was more beneficial to the biological response (implant bone ongrowth) at the cancellous site, but was only advantageous at superficial cortex depths. Internal cooling provided a distinct benefit at the deeper drill levels in compact bone. At later timepoints of 8 and 16 weeks no appreciable differences were observed between the sites as a function of irrigation type. The result obtained from the cancellous site adds strength to the argument that externally applied coolant may limit maximal temperature elevation even in the advanced stage of drilling (Lee, Rabin et al. 2011), such as at the far cortex in the case of bi-cortical drilling. Admittedly, little research has been directed at the temperature elevation in cancellous bone during drilling, with most if not all research having been conducted in a compact bone bed.

Pre-drilling and pilot hole creation are other methods which have been advocated to reduce the biological effects of heat generated during drilling (Matthews and Hirsch 1972). Using dental burs, however, Reinewirtz et al (Reingewirtz, Szmukler-Moncler et al. 1997) were unable to convey a benefit in terms of reduced temperature elevation but did observe a reduction in the drilling time. Sequential drilling at larger diameters is also performed to reduce maximal temperatures (Bubeck, Garcia-Lopez et al. 2009). Intermittent drilling/burring has also been advocated as a means to reduce maximal temperature elevation (Kondo, Okada et al. 2000).

\subsection{Post-operative complications}

\subsubsection{Broken drill-bit portions}

In today's medicolegal environment there have been several reported cases of compensation received by patients and fines issued to hospitals as a result of broken drill-bits left in situ without the patient's knowledge (Burruss 2010). Despite this there are still surgeons who do not routinely inform their patients of intraoperative drill bit failure. There are no reports in the literature of adverse reactions to portions of broken drill-bit which have been left in situ causing morbidities which have necessitated re-operation for removal, which is representative of the biologically inert nature of the materials used in drill-bit manufacture.

\subsubsection{Thermonecrosis and failure of implant fixation}

A by-product of the drilling process is the generation of heat energy, which causes a transient increase in temperature of the bone and soft tissues as well as the drill-bit itself. Whilst there is no consensus regarding critical values or their durations an increase above $47^{\circ} \mathrm{C}$ of the cortical bone has been implicated with a reduced regenerative capacity and osteonecrosis (Lundskog 1972; Matthews and Hirsch 1972; Eriksson and Albrektsson 1983; Eriksson and Albrektsson 1984; Eriksson, Albrektsson et al. 1984b). Despite an acute awareness of the association between drilling and temperature rises in bone there are few reports in the clinical orthopaedic literature of complications or implant failures which could be attributed to this. One notable exception was a recent report by Berning et al (Berning and Fowler) presenting a case of a patient having osteomyelitis of the proximal tibia due to thermal necrosis following tracker pin placement in computer-navigated total knee arthroplasty. In fact, it appears that most of the evidence in the literature pertaining to thermonecrosis could most suitably be described as being anecdotal. A major limitation in determining thermonecrosis has occurred as a result of surgical intervention and drilling is a lack of hard evidence. Radiographic presentation of thermonecrosis is denoted by the presence of a phenomenon known as ring sequestrum around a drill hole (Figure 12). 
Thermonecrosis remains a cause for concern for surgeons in the case of cemented fixation of components in joint arthroplasty also. The polymerisation of bone cement (Polymethylmethacrylate, PMMA) is an exothermic reaction in which a significant amount of heat energy is released. These excessive temperatures can lead to the resorption of bone adjacent to the cement mantle which can result in aseptic loosening of implants and failure of joint prostheses. Despite several research efforts there still remains a lack of consensus in the literature regarding critical temperature values and their durations. PMMA cement is also widely used to fill orthotopic defects which have arisen from the removal of tumours and compression fractures. One example is the utilisation of PMMA by spinal surgeons to stabilise osteoporotic compression fractures of the vertebral body, where temperatures in the cortex can reach $113^{\circ} \mathrm{C}$ (Belkoff and Molloy 2003).

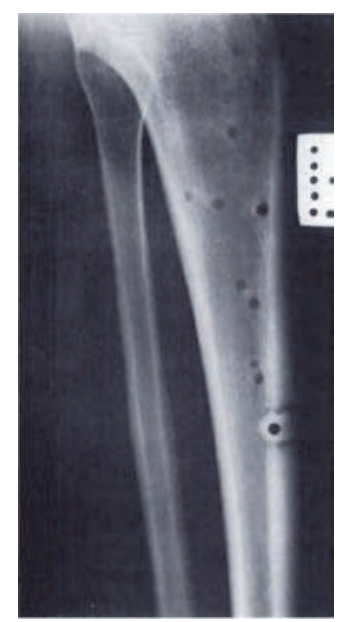

Fig. 12. Radiographic appearance of thermal necrosis as ring sequestrum. Image obtained following in vitro testing of human cadaveric tibiae (Matthews, Green et al. 1984)

\section{Biological models in thermonecrosis research}

Animal models have been heavily utilised to explore the effects of elevated temperatures on the viability of cells and bone. The obvious benefit to the use of animals in research is the availability of affected and control tissues for the experimental endpoints. Specifically, in vivo studies have been conducted in the ovine, laprine, porcine and canine models, and it appears that the extent of the effects which heat has on bone tissue depends on the maximal temperature attained and duration of the exposure. Of particular interest in these studies is viability of cortical bone following a thermal insult, with a histological hallmark of osteonecrosis being the presence of empty osteocyte lacunae (Eriksson, Albrektsson et al. 1984b; Franssen, van Diest et al. 2008) (Figure 13).

Using rabbits, Eriksson et al (Eriksson, Albrektsson et al. 1984b) created full-thickness defects in the femoral diaphysis using a $3 \mathrm{~mm}$ diameter drill-bit at 20,000rpm with irrigation. In the same cohort of animals, fibulae were resected and excised and placed into heated saline baths maintained at $47^{\circ}, 50^{\circ}, 56^{\circ}$ and $60^{\circ}$ for 1 minute. Animals were sacrificed immediately following the procedure and cylindrical defect sites processed histologically 
where it was found that surrounding each of the defects was a $200 \mu \mathrm{m}$ radial zone of empty osteocyte lacunae. Immunohistological analysis of the tissue, however, painted a more severe picture of detrimental changes in the bone surrounding the defect. Using this method the necrotical border appeared to be radially dispersed at an average of $500 \mu \mathrm{m}$, as determined by the absence of diaphorase enzyme activity. These intracellular enzymes are produced only by metabolically active cells. In an earlier study Eriksson and Albrektsson (Eriksson and Albrektsson 1983) performed a study in rabbits in which the cortical bone was heated to $47^{\circ} \mathrm{C}$ for varying durations and found the development of osteonecrosis with exposure for 1 minute. Lundskog (Lundskog 1972) observed that if bone is exposed to temperatures above $50^{\circ} \mathrm{C}$ for 30 s cellular necrosis will occur.

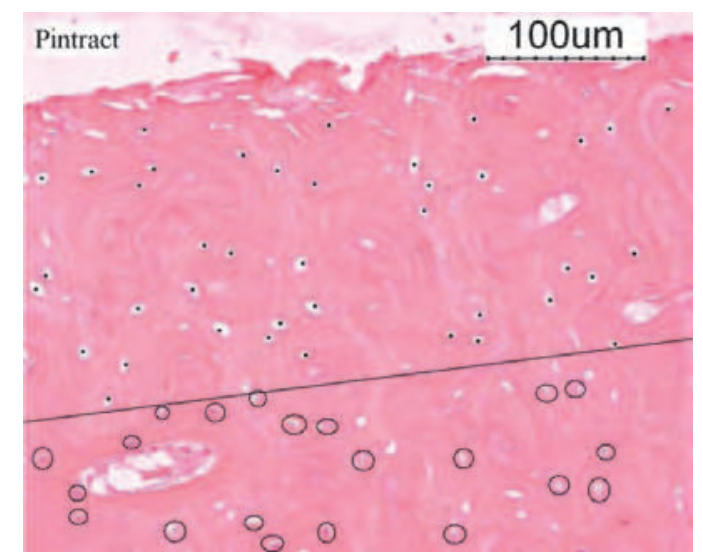

Fig. 13. Histological image (hematoxylin and eosin stain) depicting necrotic bone adjacent to a pintract denoted by the presence of empty osteocyte lacunae (dots). Healthy osetocytes (circled) are also evident. (Franssen, van Diest et al. 2008)

Franssen et al (Franssen, van Diest et al. 2008) investigated the biological effects of k-wire implantation on the viability of cortical bone in rabbits. Using a carefully constructed jig, trochar-tipped k-wires were drilled into the tibiae and femur under a constant load and speed of $1.5 \mathrm{~kg}$ and $1200 \mathrm{rpm}$, respectively. Evidence of osteonecrosis, denoted by the presence of empty osteocyte lacunae was evident immediately following recovery and at 4 weeks postoperatively (Figure 13). Ardan and co-workers (Ardan, Janes et al. 1957) heated surgically-created defects in canine femurs ultrasonically and detected delayed unions in addition to osteonecrosis.

The effect of exposure to heat on the osteogenic potential for healing and bone formation has also been explored using animal models. In rabbits, Ohashi and colleagues (Ohashi, Therin et al. 1994a) found bone formation in $4 \mathrm{~mm}$ diameter defects prepared in the cortical bone of the tibia with a rotation speed of 5000rpm was significantly less that that associated with $500 \mathrm{rpm}$. The authors attributed this result to the presence of thermonecrosis and vascular obstructions at the margin of the defect site. In a second cohort of animals cylindrical defects were created using the same conditions and drill type but which were subsequently filled with porous HA implant dowels (Ohashi, Therin et al. 1994c). The purpose of this study was to examine the effects of site preparation and osteotomy on the bony response to the implantation of an osteoconductive biomaterial, as would be the case for uncemented 
fixation of implants in joint arthroplasty. As their earlier result had intimated an increased amount of bone ingrowth associated with the HA dowels implanted into $3.3 \mathrm{~mm}$ diameter defects created at $500 \mathrm{rpm}$ versus those prepared at $5000 \mathrm{rpm}$ was detected 4 weeks postoperatively. By 12 weeks, however, the differential in bone formation between sites, which was significant, had diminished, suggesting high speed drilling affects the short-term bony response to biomaterials. Ohashi's group (Ohashi, Therin et al. 1994b) also demonstrated a statistically significant dependence of the healing response on anatomical aspect, namely the radial direction, within the ovine metatarsal bone, with no difference observed in the longitudinal dimension of the bone.

Iyer et al (Iyer, Weiss et al. 1997a) measured intraoperative temperature elevation in the rabbit tibia during the preparation of $3 \mathrm{~mm}$ diameter holes using a bur at low (2500rpm), intermediate $(100,000 \mathrm{rpm})$ and high $(400,000 \mathrm{rpm})$ rotation speeds. All drilling was performed by a single surgeon, with no additional provisions being made to control axial thrust force. No quantitative analysis of the histology was performed of the tibiae but a correlation between the maximal temperature and osteogenic potential was confirmed in a later study using the same hardware and methods, again in rabbits (Iyer, Weiss et al. 1997b). Specifically, as the speed of the osteotomies increased a greater rate and better quality of bone regeneration was observed 6 weeks postoperatively. In both these studies external irrigation was applied during burring.

Our group has previously investigated the effects of heat generation on the healing response and fixation of pedicle screws (pull-out strength) in the ovine model (Bertollo, Milne et al. 2010). We tested a novel 3-fluted drill-bit against commercially-available 2- and 3-fluted drill-bits. In part 1 of the study we detected significant differences between the drills in terms of the maximal heat generation in porcine bone in vitro. Based on these results we predicted that temperatures in excess of $60^{\circ} \mathrm{C}$ would be produced during the intraoperative creation of pilot holes in the ovine tibia into which the pedicle screws were implanted. Despite in vitro differences in maximal temperatures between the drills this did not translate into a marked improvement in either the fixation of pedicle screws as determined by a mechanical pullout test or histological appearance of the screw-bone interface following 2, 4 and 6 weeks in situ. No evidence of osteonecrosis was found at the drill sites at either timepoint. Hillery and Shuaib (Hillery and Shuaib 1999) conducted an in vitro screw pullout test in cadaveric and bovine bone to determine if the temperature rise during drilling of the pilot hole had implications for time zero fixation but found no differences, despite temperatures in the vicinity of the drilled defects reaching between 102 to $117.8^{\circ} \mathrm{C}$.

Stubinger and others (Stubinger, Biermeier et al. 2010) employed an ovine model to evaluate the capabilities of alternatives to the mechanical machining of bone which have been introduced in the dental field, including Er:YAG lasers and piezoelectric devices. Defects were created in the pelvis using these methods as well as by conventional drilling. Histological and mechanical experimental endpoints confirmed that these methods were at least comparable to drill osteotomy in terms of bony response and implant fixation.

\section{Measurement methods}

Measurement of the temperature generated during drilling of bone has traditionally been performed using the classic thermocouple technique. More recently the decreased cost and increased availability of infrared thermal imaging cameras has resulted in their use for the experimental determination of temperature rises during drilling of bone (Udiljak, Ciglar et 
al. 2007; Augustin, Davila et al. 2008; Augustin, Davila et al. 2009; Bertollo, Milne et al. 2010; Yang, Wang et al. 2010). Both temporal methods of temperature measurement have their pros and cons. Infrared cameras are able to provide information regarding the distribution of temperature of the cortical bone surrounding the defect with greater resolution than is provided by a classic thermocouple nest (Augustin, Davila et al. 2009). Throughout the literature a total of three thermocouples are normally placed at increasing radial distances from the defect edge, with $0.5 \mathrm{~mm}, 1 \mathrm{~mm}$ and $3 \mathrm{~mm}$ being normal values adopted. A major limitation of the thermocouple nest method is the time involved in preparing the pilot holes for the thermocouple probes, as well as an inability to measure the temperature at the toolbone interface. Whilst this can theoretically be achieved using infrared imaging, a major limitation of this measurement method is a lack of depth perception in the data, that is, a complex three-dimensional field is simplified and reduced to a 2-dimensional planar dataset.

\section{Future directions}

Continual efforts are being directed at the improvement of drill-bit design to enhance performance for the surgeon and postoperative outcome for the patient. Ultrasonic assisted drilling is one such technology which applies ultrasonic vibrations along the longitudinal direction of the drill-bit to assist with the cutting process (Alam, Mitrofanov et al.). This technology has been shown to cause reductions in both axial thrust force and drilling torque. Feedback systems detecting real-time cortical break-through have also been developed (Allotta, Belmonte et al. 1996; Ong and Bouazza-Marouf 1998; Ong and BouazzaMarouf 1999) with the intention of minimising the effect of break-through on hole geometry as well as minimising the damage inflicted to soft tissues by the drill-tip.

Alternatives to the mechanical machining of bone have been developed for dental operations, including Er:YAG lasers and piezoelectric devices (Stubinger, Biermeier et al. 2010). Piezoelectric osteotomy is based on ultrasonic vibration of an osteotomic device that permits precise cutting of bone structures without cutting adjacent soft tissues whilst lasers cause tissue ablation. These methods have the propensity to produce defects in an atraumatic manner which may have positive implications for healing.

\section{Conclusion}

The surgical drilling of bone is associated with the generation of heat which causes a transient rise in temperature of hard and soft tissues to above normal physiological levels. Depending on the magnitude of the maximal temperature attained and the duration for which the elevated temperature is maintained thermonecrosis of bone may ensue. Bone is particularly susceptible to high temperatures as it has a relatively low thermal conductivity, the implication being that heat is not easily dissipated. Coupled with a relatively low specific heat, the end result is that the inertial effect following a localised injection of heat can be considerable. The general consensus is that a temperature of $47^{\circ} \mathrm{C}$ is the critical threshold limit for thermonecrosis to occur in compact bone. This can have severe and dire implications for implant fixation as a result of osteoclastic resorption of necrotic bone. Osteogenic potential can also be compromised due to exposure to elevated temperatures which can hinder tissue infiltration and osseointegration required for biological fixation of implants, such as in uncemented joint arthroplasty. 
The extent of the temperature rise during drilling in bone is affected by a number of operational and geometric variables, all of which have been studied extensively in the literature. Perhaps the most salient of the geometric variables, and certainly that which is reported consistently is dulling and wear of the cutting edges through repeated use which increases the axial thrust force required to propel the machining face through bone, causing a marked increase in maximal temperature elevation. Inevitably, imposing additional demand upon the surgeon compromises control which they are able to exert over the handpiece, that is, additional force increases the probability of uncontrolled plunging of the tip as well as cortical break-through. For all intents and purposes surgical drills are multiple use items, and a lack of routine monitoring in the hospital sterilisation departments may be the reason for blunted drill-bits remaining in circulation. Certainly, in our home country (Australia) a common complaint voiced by surgeons is the frequent encountering of dulled and blunted bits in clinical practice.

Operational variables affecting temperature elevation in bone are primarily axial thrust force and rotation speed. Many fundamental differences in the studies which have been performed regarding this rise during drilling exist. Firstly, they originate from many different surgical sub-specialities where there are subtle differences in hardware and protocol. Secondly, there is a considerable range in rotation speeds which have been investigated. High speed drilling and burring (2000 to $400,000 \mathrm{rpm}$ ) is more pertinent to the dental and orthodontic applications whilst in orthopaedics speeds of typically less than 1000rpm are employed. Although the data which has been advanced in the literature is sometimes contradictory regarding the effects of these parameters, in general, increasing feed rate has been shown to decrease maximal temperature whilst increasing rotation speed has been shown to produce an increase. Intuitively, one would surmise that in the context of a finite cortical thickness a reduction in temperature would be realised based purely on a reduction in drilling time. If the transfer of heat during drilling is considered as time-dependent heat flux then it stands to reason that a reduction in drilling time reduces the heat energy injected into the system and, in turn, the maximum temperature attained.

There is definite agreement in the literature that temperatures well in excess of $100^{\circ} \mathrm{C}$ are possible during the surgical drilling of bone. Temperature abatement measures have been applied clinically, with the most effective strategy being the application of coolant. Sequential drilling has also been advocated to reduce temperatures, but which has the drawback of increased surgical time, and this can have considerable compounding effects. The heat generated during drilling in the absence of temperature abatement measures such as irrigation are comparable with those encountered during the curing of polymethylmethacrylate (bone cement). This material is heavily utilised in joint arthroplasty surgery for fixation of joint prostheses components to surgically-resected bone. Temperature abatement during the in situ polymerisation of PMMA bone cement is effectively an operational impossibility.

Both 2- and 3-fluted drills are in clinical use. Reports in the literature seem to suggest that diameter matched 3-fluted drills are more efficient than their 2-fluted counterparts. As has been demonstrated a reduction in drilling time due to increased feed rate can limit the magnitude of the temperature rise in bone. Three-fluted drills are also inherently stiffer and are less likely to fail under the application of a bending moment. Despite these potential benefits their use remains limited in surgical procedures entailing the cutting of bone. 


\section{References}

Abouzgia, M. B. and D. F. James (1995). Measurements of shaft speed while drilling through bone. Journal of Oral and Maxillofacial Surgery 53(11): 1308-1315.

Abouzgia, M. B. and J. M. Symington (1996). Effect of drill speed on bone temperature. International Journal of Oral \& Maxillofacial Surgery 25(5): 394-399.

Alam, K., A. V. Mitrofanov et al. Experimental investigations of forces and torque in conventional and ultrasonically-assisted drilling of cortical bone. Medical Engineering \& Physics (In Press).

Allan, W., E. D. Williams et al. (2005a). Effects of repeated drill use on temperature of bone during preparation for osteosynthesis self-tapping screws. British Journal of Oral and Maxillofacial Surgery 43(4): 314-319.

Allan, W., E. D. Williams et al. (2005b). Effects of repeated drill use on temperature of bone during preparation for osteosynthesis self-tapping screws. British Journal of Oral \& Maxillofacial Surgery 43(4): 314-319.

Allotta, B., F. Belmonte et al. (1996). Study on a mechatronic tool for drilling in the osteosynthesis of long bones: Tool/bone interaction, modeling and experiments. Mechatronics 6(4): 447-459.

Anonymous (2008). High-speed surgical drills may overheat and cause burns. Health Devices 37(7): 213-215.

Ardan, N. I. J., J. M. Janes et al. (1957). Ultrasonic energy and surgically produced defects in bone. J Bone Joint Surg Am 39-A(2): 394-402.

Ashford, R. U., K. C. Pande et al. (2001). Current practice regarding re-use of trauma instrumentation: results of a postal questionnaire survey. Injury 32: 37-40.

Augustin, G., S. Davila et al. (2008). Thermal osteonecrosis and bone drilling parameters revisited. Archives of Orthopaedic \& Trauma Surgery 128(1): 71-77.

Augustin, G., S. Davila et al. (2009). Determination of spatial distribution of increase in bone temperature during drilling by infrared thermography: preliminary report. Archives of Orthopaedic \& Trauma Surgery 129(5): 703-709.

Bachus, K. N., M. T. Rondina et al. (2000). The effects of drilling force on cortical temperatures and their duration: an in vitro study. Medical Engineering \& Physics 22(10): 685-691.

Bassi, J. L., M. Pankaj et al. (2008). A technique for removal of broken cannulated drill bit: Bassi's method. Journal of Orthopaedic Trauma 22(1): 56-58.

Belkoff, S. M. and S. Molloy (2003). Temperature measurement during polymerization of polymethylmethacrylate cement used for vertebroplasty.[see comment]. Spine 28(14): 1555-1559.

Benirschke, S. K., I. Melder et al. (1993). Closed interlocking nailing of femoral shaft fractures: assessment of technical complications and functional outcomes by comparison of a prospective database with retrospective review. J Orthop Trauma 7(2): 118-122.

Berning, E. T. and R. M. Fowler Thermal Damage and Tracker-Pin Track Infection in Computer-Navigated Total Knee Arthroplasty. The Journal of Arthroplasty (Epub ahead of print)

Bertollo, N., T. K. Gothelf et al. (2008). 3-Fluted orthopaedic drills exhibit superior bending stiffness to their 2-fluted rivals: Clinical implications for targeting ability and the incidence of drill-bit failure. Injury 39(7): 734-741. 
Bertollo, N., M. Matsubara et al. (2011). Effect of Surgical Fit on Integration of Cancellous Bone and Implant Cortical Bone Shear Strength for a Porous Titanium. Journal of Arthroplasty (In Press).

Bertollo, N., H. R. Milne et al. (2010). A Comparison of the Thermal Properties of 2- and 3Fluted Drills and the Effects on Bone Cell Viability and Screw Pull-out Strength in an Ovine Model. Clinical Biomechanics 25(6): 613-617.

Bodner, L., Y. Woldenberg et al. (2007). Drill failure during ORIF of the mandible. Complication management. Med Oral Patol Oral Cir Bucal 12(8): E591-593.

Bonfield, W. and C. H. Li (1968). The temperature dependence of the deformation of bone. J Biomech 1(4): 323-329.

Brisman, D. L. (1996). The effect of speed, pressure, and time on bone temperature during the drilling of implant sites. International Journal of Oral \& Maxillofacial Implants 11(1): 35-37.

Bubeck, K. A., J. Garcia-Lopez et al. (2009). In vitro comparison of cortical bone temperature generation between traditional sequential drilling and a newly designed step drill in the equine third metacarpal bone. Veterinary \& Comparative Orthopaedics \& Traumatology 22(6): 442-447.

Burruss, L. (2010). Hospital: Drill-bit piece accidentally left in patient's head: http://edition.cnn.com/2010/HEALTH/2010/2014/rhode.island.drill.bit/index.h tml.

Camargo, F. P., R. Faria et al. (2007). Poster \#2780: Heat Production by Drilling Bone Tissue for Implant Procedures. Annual Meeting of the International Association for Dental Research, Ernest N. Morial Convention Cente, New Orleans, LA USA.

Chacon, G. E., D. L. Bower et al. (2006). Heat production by 3 implant drill systems after repeated drilling and sterilization. Journal of Oral \& Maxillofacial Surgery 64(2): 265-269.

Chen, H. L. and A. A. Gundjian (1976). Specific heat of bone. Medical \& Biological Engineering 14(5): 548-550.

Cordioli, G. and Z. Majzoub (1997). Heat generation during implant site preparation: an in vitro study. International Journal of Oral \& Maxillofacial Implants 12(2): 186-193.

Darvish, K., M. Shafieian et al. (2009). The effect of tip geometry on the mechanical performance of unused and reprocessed orthopaedic drill bits Proceedings of the Institution of Mechanical Engineers, Part H: Journal of Engineering in Medicine 223(5): 625-635.

Davidson, S. R. and D. F. James (2003). Drilling in bone: modeling heat generation and temperature distribution. Journal of Biomechanical Engineering 125(3): 305-314.

Davidson, S. R. H. and D. F. James (2000). Measurement of thermal conductivity of bovine cortical bone. Medical Engineering \& Physics 22(10): 741-747.

Easton, M. R. and P. V. Prewitt (1937). Ununited fracture treated by bone drilling. Journal of Bone \& Joint Surgery - American Volume 19: 230-231.

Ercoli, C., P. D. Funkenbusch et al. (2004). The influence of drill wear on cutting efficiency and heat production during osteotomy preparation for dental implants: a study of drill durability. International Journal of Oral \& Maxillofacial Implants 19(3): 335349.

Eriksson, A. R. and T. Albrektsson (1983). Temperature threshold levels for heat-induced bone tissue injury: A vitalmicroscopic study in the rabbit. J Prosth Dent 50(1): 101107. 
Eriksson, A. R., T. Albrektsson et al. (1984a). Heat caused by drilling cortical bone. Temperature measured in vivo in patients and animals. Acta Orthop Scand. 55(6): 629-631.

Eriksson, R. A. and T. Albrektsson (1984). The effect of heat on bone regeneration: an experimental study in the rabbit using the bone growth chamber. Journal of Oral \& Maxillofacial Surgery 42(11): 705-711.

Eriksson, R. A., T. Albrektsson et al. (1984b). Assessment of bone viability after heat trauma. A histological, histochemical and vital microscopic study in the rabbit. Scandinavian Journal of Plastic \& Reconstructive Surgery 18(3): 261-268.

Fothi, U., S. M. Perren et al. (1992). Drill bit failure with implant involvement - an intraoperative complication in orthopaedic surgery. Injury 23(SUPPL. 2): S17-S29.

Franssen, B. B. G. M., P. J. van Diest et al. (2008). Drilling K-wires, what about the osteocytes? An experimental study in rabbits. Archives of Orthopaedic \& Trauma Surgery 128(1): 83-87.

Garcia, O. G. R., F. L. Mombiela et al. (2004). The influence of the size and condition of the reamers on bone temperature during intramedullary reaming. Journal of Bone \& Joint Surgery - American Volume 86-A(5): 994-999.

Gupta, R. K., H. Singh et al. (2009). Results of operative treatment of acetabular fractures from the Third World-how local factors affect the outcome. International Orthopaedics 33: 347-352.

Haider, R., G. Watzek et al. (1993). Effects of drill cooling and bone structure on IMZ implant fixation. Int J Oral Maxillofac Implants 8(1): 83-91.

Harris, B. H. and S. S. Kohles (2001). Effects of mechanical and thermal fatigue on dental drill performance. International Journal of Oral \& Maxillofacial Implants 16(6): 819826.

Hillery, M. T. and I. Shuaib (1999). Temperature Effects in the Drilling of Human and Bovine Bone. Journal of Materials Processing Technology 92-93: 302-308.

Hirt, U., J. A. Auer et al. (1992). Drill bit failure without implant involvement - an intraoperative complication in orthopaedic surgery. Injury 23(SUPPL. 2): S5-S16.

Hobkirk, J. A. and K. Rusiniak (1977). Investigation of variable factors in drilling bone. J Oral Surg. 35(12): 968-973.

Iyer, S., C. Weiss et al. (1997a). Effects of drill speed on heat production and the rate and quality of bone formation in dental implant osteotomies. Part I: Relationship between drill speed and heat production. International Journal of Prosthodontics 10(5): 411-414.

Iyer, S., C. Weiss et al. (1997b). Effects of drill speed on heat production and the rate and quality of bone formation in dental implant osteotomies. Part II: Relationship between drill speed and healing. International Journal of Prosthodontics 10(6): 536540 .

Jackson, C. J., S. K. Ghosh et al. (1989). On the evolution of drill-bit shapes. Journal of Mechanical Working Technology 18(2): 231-267.

Jacob, C. H. and J. T. Berry (1976). A study of the bone machining process--drilling. J Biomech: 343-349.

Jacob, C. H., M. H. Pope et al. (1974). A study of the bone machining process-orthogonal cutting. J Biomech 7(2): 131-136.

Jacobs, C. H., M. H. Pope et al. (1974). A study of the bone machining process-orthogonal cutting. J Biomech 7(2): 131-136. 
Jochum, R. M. and P. A. Reichart (2000). Influence of multiple use of Timedur-titanium cannon drills: thermal response and scanning electron microscopic findings. Clin Oral Implants Res. 11(2): 139-143.

Kondo, S., Y. Okada et al. (2000). Thermological Study of Drilling Bone Tissue with a Highspeed Drill. Neurosurgery 46(5): 1162-1168.

Kosy, J. D. and D. M. Standley (2010). Retrieval of a Broken Acutrack Drill Bit. Journal of Hand Surgery: European Volume 35: 683.

Krause, W. R., D. W. Bradbury et al. (1982). Temperature elevations in orthopaedic cutting operations. J Biomech 15(4): 267-275.

Larsen, S. T. and L. Ryd (1989). Temperature elevation during knee arthroplasty. Acta Orthopaedica Scandinavica 60(4): 439-442.

Lavelle, C. and D. Wedgwood (1980). Effect of internal irrigation on frictional heat generated from bone drilling. J Oral Surg 38: 499-503.

Lee, J., Y. Rabin et al. (2011). A New Thermal Model for Bone Drilling with Applications to Orthopaedic Surgery. Medical Engineering \& Physics (Article in Press).

Lundskog, J. (1972). Heat and Bone Tissue. An Experimental Investigation of the Thermal Properties of Bone and Threshold Levels for Thermal Injury. Supplement 9. Scand J Plastic Reconst Surg.

Marciniak, J., Z. Z. Paszenda et al. (2007). Wear Investigation of Tools Used in Bone Surgery. Journal of Achievements in Materials and Manufacturing Engineering 20(1-2): 259262.

Matthews, L. S., C. A. Green et al. (1984). The thermal effects of skeletal fixation-pin insertion in bone. Journal of Bone \& Joint Surgery - American Volume 66(7): 10771083.

Matthews, L. S. and C. Hirsch (1972). Temperatures measured in human cortical bone when drilling. J Bone Joint Surg Am 54A: 297-308.

Matthews, S. J., R. E. Landsmeer et al. (2006). Removal of Broken Drill Bits and Locking Screws from an Intramedullary Nail. Annals of the Royal College of Surgeons of England 88(3): 316.

Miller, M. D. (2002). EndoButton drill bit failure. Arthroscopy 18(3): 322-324.

Narasimha, K., M. O. M. Osman et al. (1987). An investigation into the influence of helix angle on the torque-thrust coupling effect in twist drills. The International Journal of Advanced Manufacturing Technology 2(4): 91-105.

Natali, C., P. Ingle et al. (1996). Orthopaedic bone drills-can they be improved? Temperature changes near the drilling face. Journal of Bone and Joint Surgery 78-B(3): 357-362.

Ohashi, H., M. Therin et al. (1994a). The effect of drilling parameters on bone. Part I General healing response. Journal of Materials Science: Materials in Medicine 5(4): 225-231.

Ohashi, H., M. Therin et al. (1994b). The effect of drilling parameters on bone. Part II The influence of drilling site. Journal of Materials Science: Materials in Medicine 5(4): 232-236.

Ohashi, H., M. Therin et al. (1994c). The effect of drilling parameters on bone. Part III The response to porous hydroxyapatite implants. Journal of Materials Science: Materials in Medicine 5(4): 237-241.

Ong, F. R. and K. Bouazza-Marouf (1998). Drilling of bone: a robust automatic method for the detection of drill bit break-through. Proceedings of the Institution of Mechanical Engineers Part H - Journal of Engineering in Medicine 212(3): 209-221. 
Ong, F. R. and K. Bouazza-Marouf (1999). The detection of drill bit break-through for the enhancement of safety in mechatronic assisted orthopaedic drilling. Mechatronics 9(6): 565-588.

Pichler, W., P. Mazzurana et al. (2008). Frequency of instrument breakage during orthopaedic procedures and its effects on patients. Journal of Bone \& Joint Surgery - American Volume 90(12): 2652-2654.

Pinczewski, L. A., J. Lyman et al. (2007). A 10-Year Comparison of Anterior Cruciate Ligament Reconstructions With Hamstring Tendon and Patellar Tendon Autograft: A Controlled, Prospective Trial. American Journal of Sports Medicine 35: 564-574.

Piska, M., L. Yang et al. (2002). Drilling efficiency and temperature elevation of three types of Kirschner-wire point. Journal of Bone \& Joint Surgery - British Volume 84(1): 137-140.

Price, M. V., S. Molloy et al. (2002). The rate of instrument breakage during orthopaedic procedures. Int Orthop 26(3): 185-187.

Reingewirtz, Y., S. Szmukler-Moncler et al. (1997). Influence of different parameters on bone heating and drilling time in implantology. Clin Oral Implants Res. 8(3): 189-197.

Saha, S., S. Pal et al. (1982). Surgical drilling: design and performance of an improved drill. Journal of Biomechanical Engineering 104(3): 245-252.

Sener, B. C., G. Dergin et al. (2009). Effects of irrigation temperature on heat control in vitro at different drilling depths. Clin Oral Implants Res. 20(3): 294-298.

Sharawy, M., C. E. Misch et al. (2002). Heat generation during implant drilling: the significance of motor speed. Journal of Oral \& Maxillofacial Surgery 60(10): 1160-1169.

Silverstein, C. C. (2007). Self-Cooling Cavity Burs for Surgical Drills. Journal of Medical Devices 1(4): 293-296.

Singh, J., J. H. Davenport et al. (2010). A national survey of instrument sharpening guidelines. The Surgeon 8(3): 136-139.

Steeves, M., C. Stone et al. (2005). How pilot-hole size affects bone-screw pullout strength in human cadaveric cancellous bone. Canadian Journal of Surgery 48(3): 207-212.

Stephenson, D. A. and J. S. Agapiou (1997). Metal Cutting Theory and Practice.

Stubinger, S., K. Biermeier et al. (2010). Comparison of Er:YAG laser, piezoelectric, and drill osteotomy for dental implant site preparation: a biomechanical and histological analysis in sheep. Lasers Surg Med 42(7): 652-661.

Svehla, M., P. Morberg et al. (2002). The effect of substrate roughness and hydroxyapatite coating thickness on implant shear strength. The Journal of Arthroplasty 17(3): 304-311.

Svehla, M., P. Morberg et al. (2000). Morphometric and mechanical evaluation of titanium implant integration: comparison of five surface structures. J Biomed Mater Res 51(1): 15-22.

Toews, A. R., J. V. Bailey et al. (1999). Effect of feed rate and drill speed on temperatures in equine cortical bone. American Journal of Veterinary Research 60(8): 942-944.

Udiljak, T., D. Ciglar et al. (2007). Investigation into Bone Drilling and Thermal Bone Necrosis. Advances in Production Engineering and Management 2(3): 103-112.

Ueda, T., A. Wada et al. (2010). The Effect of Drill Design Elements on Drilling Characteristics when Drilling Bone. Journal of Biomechanical Science and Engineering 5(4): 399-407.

Wolfson, K. A., L. L. Seeger et al. (2000). Imaging of Surgical Paraphernalia: What Belongs in the Patient and What Does Not. Radiographics 20(6).

Yang, Y., C. Wang et al. (2010). Drilling Force and Temperature of Bone by Surgical Drill. Advanced Materials Research 126-128: 779-784. 


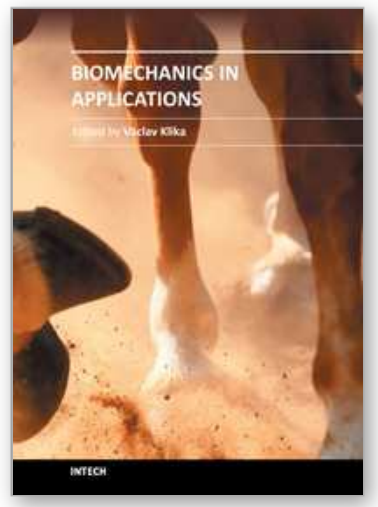

\author{
Biomechanics in Applications \\ Edited by Dr Vaclav Klika
}

ISBN 978-953-307-969-1

Hard cover, 408 pages

Publisher InTech

Published online 09, September, 2011

Published in print edition September, 2011

During last couple of years there has been an increasing recognition that problems arising in biology or related to medicine really need a multidisciplinary approach. For this reason some special branches of both applied theoretical physics and mathematics have recently emerged such as biomechanics, mechanobiology, mathematical biology, biothermodynamics. The Biomechanics in Application is focusing on experimental praxis and clinical findings. The first section is devoted to Injury and clinical biomechanics including overview of the biomechanics of musculoskeletal injury, distraction osteogenesis in mandible, or consequences of drilling. The next section is on Spine biomechanics with biomechanical models for upper limb after spinal cord injury and an animal model looking at changes occurring as a consequence of spinal cord injury. Section Musculoskeletal Biomechanics includes the chapter which is devoted to dynamical stability of lumbo-pelvi-femoral complex which involves analysis of relationship among appropriate anatomical structures in this region. The fourth section is on Human and Animal Biomechanics with contributions from foot biomechanics and chewing rhythms in mammals, or adaptations of bats. The last section, Sport Biomechanics, is discussing various measurement techniques for assessment and analysis of movement and two applications in swimming.

\title{
How to reference
}

In order to correctly reference this scholarly work, feel free to copy and paste the following:

Nicky Bertollo and William Robert Walsh (2011). Drilling of Bone: Practicality, Limitations and Complications Associated with Surgical Drill-Bits, Biomechanics in Applications, Dr Vaclav Klika (Ed.), ISBN: 978-953-307969-1, InTech, Available from: http://www.intechopen.com/books/biomechanics-in-applications/drilling-of-bonepracticality-limitations-and-complications-associated-with-surgical-drill-bits

\section{INTECH}

open science / open minds

\section{InTech Europe}

University Campus STeP Ri

Slavka Krautzeka 83/A

51000 Rijeka, Croatia

Phone: +385 (51) 770447

Fax: +385 (51) 686166

www.intechopen.com

\section{InTech China}

Unit 405, Office Block, Hotel Equatorial Shanghai

No.65, Yan An Road (West), Shanghai, 200040, China

中国上海市延安西路 65 号上海国际贵都大饭店办公楼 405 单元

Phone: +86-21-62489820

Fax: $+86-21-62489821$ 
(C) 2011 The Author(s). Licensee IntechOpen. This chapter is distributed under the terms of the Creative Commons Attribution-NonCommercialShareAlike-3.0 License, which permits use, distribution and reproduction for non-commercial purposes, provided the original is properly cited and derivative works building on this content are distributed under the same license. 